\title{
LA PENA DE INHABILITACIÓN ESPECIAL PARA EMPLEO O CARGO PÚBLICO EN EL ÁMBITO DE LOS DELITOS DE CORRUPCIÓN RELACIONADOS CON LA CONTRATACIÓN PÚBLICA
}

\author{
Luz María Puente Aba ${ }^{1}$
}

Resumen: La pena de inhabilitación especial para empleo o cargo público constituye una sanción especialmente idónea para los delitos de corrupción en el marco de la contratación pública. En este trabajo se pretende atender a diversas problemáticas planteadas en la aplicación de esta pena. Se analizará el significado de "cargo público", y se prestará atención al desarrollo de diversas funciones relacionadas con la Administración pública: la actuación en el marco de sociedades mercantiles públicas y de corporaciones sectoriales de base privada, y en la ejecución de un contrato administrativo. También se tratarán otras cuestiones como los criterios para determinar los cargos o empleos análogos a aquellos que son objeto de privación, la posibilidad de seleccionar determinados ámbitos o actividades del empleo o cargo, o cómo aplicar la pena cuando el condenado posee más de un empleo o cargo público, o por el contrario no posee ninguno.

Recibido: agosto 2019. Aceptado: febrero 2020

1 Profesora Titular de Derecho Penal. Orcid ID 0000-0001-9509-7770

Departamento de Derecho Público. Facultad de Derecho de la Universidade da Coruña. Campus Elviña s/n 15071 A Coruña. E-mail: lpuente@udc.es 
Palabras clave: Inhabilitación especial, penas privativas de derechos, corrupción, empleos públicos, cargos públicos.

\title{
THE PENALTY OF CIVIL DISQUALIFICATION FOR PUBLIC EMPLOYMENT OR PUBLIC SERVICE POSITIONS, IN THE FIELD OF CORRUPTION CRIMES REGARDING PUBLIC PROCUREMENT
}

\begin{abstract}
The penal sanction of civil disqualification is especially suitable for corruption crimes related to public procurement. This paper tackles some controversial questions regarding the implementation of this sanction. First, we define "Public service position" and address some specific functions of Public Administration, such as those related to publicly traded companies, corporations, and the execution of an administrative contract. Second, we analyse specific criteria used by judges to: select analogous employment or positions the convicted person is barred from engaging in; potentially determine some specific fields or activities the convicted person may still engage in with relation to the employment or position; implement this sanction when the convicted person has more than one public position, or contrarily no public position at all.
\end{abstract}

Key words: Civil disqualification, deprivation of rights, corruption, public servants, public service positions.

\section{Introducción}

La pena de inhabilitación especial para empleo o cargo público se configura como una sanción especialmente idónea para los delitos de corrupción en la Administración pública. En este trabajo se pretende hacer un examen de los problemas de aplicación de esta pena, analizándola específicamente en relación con delitos de corrupción en el marco de la contratación pública. De hecho, si seleccionamos aquellas figuras delictivas que pueden guardar una más estrecha relación con comportamientos de corrupción en el ámbito de la contratación pública, puede identificarse un reducido grupo en el que solo aparecen 
previstas, como penas principales, penas privativas de derechos y multa (esto es, excluyendo la privación de libertad): la prevaricación (art. $404 \mathrm{CP}$ ), cuyas penas principales son la inhabilitación especial para empleo o cargo público y la inhabilitación para el derecho de sufragio pasivo; falsedad contable y revelación de información económica mendaz (art. 433 bis aps. 1 y $2 \mathrm{CP}$ ), donde se prevén las penas de inhabilitación especial para empleo o cargo público y multa; y cohecho pasivo (arts. 419, 420 y 421 CP), tráfico de influencias (arts. 428 y $430 \mathrm{CP}$ ), malversación (art. 432 y $433 \mathrm{CP}$ ), fraudes ilegales (art. $436 \mathrm{CP}$ ) y negociaciones prohibidas a autoridades o funcionarios públicos (art. $439 \mathrm{CP}$ ), donde se prevé pena privativa de libertad y/o multa, inhabilitación especial para empleo o cargo público e inhabilitación para el derecho de sufragio pasivo².

Aquí se pretende atender a dos tipos de problemáticas planteadas en relación con la aplicación de esta pena. Por un lado, se tratarán cuestiones generales relativas a la definición y ejecución de esta sanción que, a pesar de su carácter básico, distan de estar resueltas y perfeccionadas en su aplicación judicial, no solo por el carácter secundario que tradicionalmente parece imprimirse a estas penas, sino también porque su inevitable vinculación con conceptos y principios extrapenales provoca la aparición de cambiantes problemas interpretativos. Así, aquí se analizará qué debe entenderse por cargo público, concepto ya de

2 Cuando en estos tipos penales el sujeto activo es un particular, no se prevé la pena de inhabilitación especial para empleo o cargo público: cohecho activo relacionado con "un procedimiento de contratación, de subvenciones o de subastas convocados por las Administraciones o entes públicos" (art. 424.3 $\mathrm{CP}$ ), tráfico de influencias realizado por particular (art. $429 \mathrm{CP}$ ), y fraudes ilegales cometidos por particular (art. $436 \mathrm{CP}$ ): se prevé pena privativa de libertad y/o multa y pena de inhabilitación para obtener subvenciones y ayudas públicas, para contratar con entes, organismos o entidades que formen parte del sector público y para gozar de beneficios o incentivos fiscales y de la Seguridad Social. Es interesante señalar también aquí que, si bien el tráfico de influencias del art. 429 CP contempla la inhabilitación para contratar con el sector público, y para obtener subvenciones y beneficios fiscales o de la Seguridad Social, en cambio el delito de "oferta de influencias" del art. $430 \mathrm{CP}$, cometido por particular, solo está castigado con pena de prisión. 
por sí de contornos indefinidos, y que además está estrechamente vinculado con el concepto de "lo público", variable tanto en la forma como en el fondo a lo largo del tiempo. Dentro de este punto, se prestará atención al desarrollo de diversas funciones relacionadas con la Administración pública, en cuyo ejercicio puede manifestarse la comisión de determinados comportamientos corruptos en relación con la contratación pública: la naturaleza de las funciones desempeñadas por quienes actúan en el seno de sociedades mercantiles públicas, y también en las denominadas corporaciones sectoriales de base privada; y también, de forma específica, el carácter de la actividad realizada por un particular (persona física o jurídica) en el marco de la ejecución de un contrato del sector público de naturaleza administrativa.

La pena de inhabilitación especial tiene dos efectos bien diferenciados: por un lado, la privación definitiva de uno o varios empleos o cargos concretos, y por otro lado, la incapacidad de acceder a ese o esos empleos o cargos, y a otros análogos, durante el tiempo de la condena. Como se puede deducir, ello requiere una especial concreción en el fallo condenatorio: en primer lugar, se ha de indicar expresamente cuál es el cargo o empleo objeto de privación (o cuáles son, en el caso de que más de uno resulte afectado), y en segundo lugar, se ha de explicitar claramente el fundamento y contenido de la analogía, esto es, cuáles son los criterios empleados para extender la prohibición de acceso a otros empleos o cargos públicos. En este trabajo se pretende analizar ambas cuestiones, no solo llamando la atención sobre la necesidad de determinar estas dos premisas básicas, a veces olvidadas en la aplicación judicial, sino también planteando específicas cuestiones problemáticas: por ejemplo, la aplicación de esta pena a particulares que no tienen ni empleos ni cargos públicos, la posibilidad de seleccionar determinados ámbitos o actividades del empleo o cargo, o cómo aplicar la pena cuando el condenado posee más de un empleo o cargo público, teniendo en cuenta la muy variada gama de situaciones que se pueden plantear en relación con esta última cuestión. Finalmente, se hace especial hincapié en el carácter definitivo del primer 
efecto de la pena (la privación del empleo o cargo público), y también en las dificultades y posibles criterios para seleccionar aquellos empleos o cargos análogos cuyo acceso estará vetado durante el tiempo que dure la condena.

\section{Los conceptos de empleos y cargos públicos}

Como premisa básica del análisis de la pena de inhabilitación especial para empleos o cargos públicos, es necesario trazar los contornos del objeto mismo de la sanción: los empleos y los cargos, ambos de carácter público. Si bien es posible ofrecer un concepto acotado de empleo público, como a continuación se verá no sucede lo mismo con los cargos públicos.

Puede afirmarse que el término empleo público abarca a todas aquellas personas que desempeñan una profesión u oficio al servicio de la Administración, a cambio de la retribución correspondiente $^{3}$. Para dotar de contenido a este concepto puede acudirse al Estatuto Básico del Empleado Público, cuyo Texto refundido fue aprobado por el Real Decreto Legislativo 5/2015, 30-10; esta norma resulta de aplicación, según su artículo 2, al personal funcionario y al personal laboral al servicio de las Administraciones Públicas. ${ }^{4}$ Más adelante, su artículo 8 clasifica

3 Vid. al respecto, por ejemplo, BAUCELLS LLADÓS, J., "Artículos 41 43”, en CÓRDOBA RODA, J./ GARCÍA ARÁN, M. (Dirs.), Comentarios al Código penal. Parte general, Marcial Pons, Madrid, 2011, pp. 463 ss.; BOLDOVA PASAMAR, M.A., en GRACIA MARTÍN, L. (Coord.), Lecciones de consecuencias jurídicas del delito, Tirant lo Blanch, Valencia, 2016, pp. 67 ss.; CARDENAL MONTRAVETA, S., “Artículo 42”, en CORCOY BIDASOlO, M. / MIR PUIG, S. (Dir.), Comentarios al Código Penal, Tirant lo Blanch, Valencia, 2015, pp. 211 ss.; PUENTE ABA, L.M., La pena de inhabilitación absoluta, Comares, Granada, 2012, p. 80, y bibliografía citada; la misma autora, "La pena de inhabilitación especial para empleo o cargo público", en FARALDO CABANA, P. / PUENTE ABA, L.M. (Dir.), Las penas privativas de derechos y otras alternativas a la privación de libertad, Tirant lo Blanch, Valencia, 2013, pp. 21 ss.

4 Como ponen de manifiesto PARADA, R. / FUENTETAJA, J., Derecho de la función pública, Civitas Thomson Reuters, Cizur Menor, 2017, pp. 162163 , el término "empleo público" es utilizado por vez primera en el ámbito 
los empleos públicos en cuatro categorías: funcionarios de carrera $^{5}$, funcionarios interinos ${ }^{6}$, personal laboral ${ }^{7}$ y personal eventual $^{8}$, si bien a estos cuatro tipos cabe añadir el personal directivo profesional, definido en el artículo 13 como aquel personal que desarrolla funciones directivas profesionales en el ámbito de las Administraciones Públicas9.

Si bien el concepto de empleo público viene perfilado en esta disposición legal, no sucede lo mismo con el de cargo pú-

de la legislación administrativa con la promulgación de la Ley 7/2007, de 12 de abril, del Estatuto básico del empleado público, que deroga casi totalmente la anterior normativa constituida por la Ley de Funcionarios Civiles del Estado (aprobada por Decreto 315/1964, de 7 de febrero), dando paso, de este modo, a la progresiva admisión de los contratos laborales en el ámbito de la Administración pública. En cualquier caso, el Código Penal (tanto el vigente como el de 1973) ya venía empleando la referencia a empleos públicos al definir las penas de inhabilitación, término que era interpretado, en el ámbito penal, admitiendo la vinculación funcionarial, laboral o administrativa con la Administración pública (cfr. BOLDOVA PASAMAR, M.A., en GRACIA MARTÍN, L. (Coord.), Tratado de las consecuencias jurídicas del delito, Tirant lo Blanch, Valencia, 2006, p. 128; LANDROVE DÍAZ, G., Las consecuencias jurídicas del delito, Tecnos, Madrid, 2005, p. 81).

5 Aquellos que, en virtud de nombramiento legal, están vinculados a una Administración Pública por una relación estatutaria regulada por el Derecho administrativo para el desempeño de servicios profesionales retribuidos de carácter permanente (artículo 9).

6 Aquellas personas nombradas por la Administración pública para desarrollar determinadas funciones propias de funcionarios de carrera cuando existan determinadas razones de justificada necesidad y urgencia (artículo 10).

7 Personas que en virtud de contrato de trabajo formalizado por escrito, en cualquiera de las modalidades de contratación de personal previstas en la legislación laboral, prestan servicios retribuidos por las Administraciones públicas (artículo 11).

8 Aquellas personas que, en virtud de nombramiento y con carácter no permanente, solo realizan funciones expresamente calificadas como de confianza o asesoramiento especial, siendo retribuidas con cargo a los créditos presupuestarios consignados para este fin (artículo 12).

9 Vid. sobre las distintas tipologías de empleos públicos en el Estatuto Básico del Empleado Público, PALOMAR OLMEDA, A. / VÁZQUEZ GARRANZO, J., Practicum Función pública 2017, Thomson Reuters, Cizur Menor, 2016, pp. 46 ss.; PARADA, R. / FUENTETAJA, J., Derecho de la función pública, cit., pp. 162 ss. 
blico. Los Tribunales han señalado que "el concepto de cargo es más anfibológico y viene a ser considerado desde la perspectiva del puesto o función pública que se desempeñaba, pero al mismo tiempo el cargo se desempeña en función de la relación de empleo de que se disfruta. [...] El cargo es el adecuado para definir la situación de los que, sin el carácter o condición de permanencia y continuidad, ostentan una función pública por elección o por cualquier otra circunstancia transitoria" (STS 426/2016, 19-5; SAP Barcelona 347/2018, 26-4).

Con carácter general, puede afirmarse que serán cargos públicos los sujetos que desempeñan alguna función de naturaleza pública por elección (popular o de una autoridad) o por cualquier otra circunstancia transitoria ${ }^{10}$. Así, el concepto de cargo público gira en torno a la ejecución de funciones o actividades públicas, pero admite muchas variantes diferentes debido a las múltiples formas en que un ciudadano puede vincularse con la Administración para, sin ser empleado público, ejercer funciones de naturaleza pública.

De entrada, no suscitan controversia los cargos públicos por elección ciudadana, como por ejemplo los miembros de las corporaciones municipales, los diputados y senadores, los integrantes de los Parlamentos autonómicos, los representantes de España en el Parlamento europeo, etc.; en cuanto a quienes ostentan un cargo público por libre elección de la autoridad competente, estamos aquí en realidad ante el llamado personal eventual, esto es, aquel tipo de empleado público que es designado para ejercer funciones, en el ámbito de la Administración pública, de confianza o asesoramiento especial.

No obstante, al margen de la facilidad de identificar los sujetos que desempeñan un cargo público por elección, ya sea popular o de una autoridad, existen algunos supuestos más difusos en los que se puede identificar a un particular que, por hallar-

10 Vid. PUENTE ABA, L.M., La pena de inhabilitación absoluta, cit., pp. 27 ss., y bibliografía citada. 
se en una determinada situación, va a participar en el ejercicio de funciones públicas sin tener la condición de empleado público. La duda está en si dentro de esta variada gama de situaciones se puede identificar la presencia de una persona que ejerce un auténtico cargo público. El elenco de las posibles situaciones de participación de una persona en la Administración pública es sin duda muy amplio ${ }^{11}$, y aquí se tratarán aquellas que más relevantes puedan resultar a efectos de la aplicación de la pena de inhabilitación con respecto a la comisión de delitos de corrupción en el marco de la contratación pública.

En primer lugar, es oportuno detenerse en las sociedades mercantiles públicas, que forman parte del denominado sector público institucional ${ }^{12}$, y que constituyen sociedades mercantiles sobre las que se ejerce control estatal en alguna de formas previstas en el art. 111 de la Ley 40/2015, 1-10, de régimen jurídico del sector público: destacadamente, a través de la participación directa en más de la mitad de su capital social ${ }^{13}$.

La creación de la variedad de entes que conforman el sector público institucional, dentro de los cuales se encuentran las sociedades mercantiles públicas, es una muestra del cómo progresivamente se van configurando diferentes tipologías de entidades destinadas a gestionar auténticos servicios públicos

11 Vid. PUENTE ABA, L.M., La pena de inhabilitación absoluta, cit., pp. 28 ss.

12 Regulado en el Título II de la Ley 40/2015, 1-10, de régimen jurídico del sector público. Según el artículo 84.1 de esta Ley, "integran el sector público institucional estatal las siguientes entidades: a) Los organismos públicos vinculados o dependientes de la Administración General del Estado, los cuales se clasifican en: $1 .^{\circ}$ Organismos autónomos. $2 .^{\circ}$ Entidades Públicas Empresariales. b) Las autoridades administrativas independientes. c) Las sociedades mercantiles estatales. d) Los consorcios. e) Las fundaciones del sector público. f) Los fondos sin personalidad jurídica. g) Las universidades públicas no transferidas".

13 Vid. con carácter general sobre las sociedades mercantiles públicas, GARCÍA DE ENTERRÍA, E. / FERNÁNDEZ, T.R., Curso de Derecho administrativo I, Civitas Thomson Reuters, Cizur Menor, 2017, pp. 460-463; PAREJO ALFONSO, L., Lecciones de Derecho administrativo, Tirant lo Blanch, Valencia, 2018, pp. 418-420; SÁNCHEZ MORÓN, M., Derecho administrativo. Parte general, Tecnos, Madrid, 2018, pp. 428 ss. 
o a desarrollar verdaderas actividades administrativas, y que se regirán obviamente por un Derecho cada vez menos público y más privado. Si bien su creación se justifica, por lo tanto, para facilitar la organización y prestación de determinadas actividades o servicios públicos específicos, se aprecia aquí la denominada "huida del Derecho administrativo"14; el legislador remite la configuración y regulación de tales entidades a sus estatutos propios, en los cuales se pueden prever excepciones a las reglas de Derecho administrativo general, que rigen para el resto de la Administración pública ${ }^{15}$. Esta diversificación, además, con-

14 Vid. a título de ejemplo sobre este fenómeno, ARIÑO ORTIZ, G. / LÓPEZ DE CASTRO, L., ¿Privatizar el Estado? Un retroceso en el camino de la Historia o la antitesis del Estado de Derecho, Fundación BBV, Bilbao, 1994; DESDENTADO AROCA, E., La crisis de identidad del Derecho Administrativo: privatización, huida de la regulación pública y Administraciones independientes, Tirant lo Blanch, Valencia, 1999, pp. 86 ss.; FERNÁNDEZ DOMÍNGUEZ, J.J. / RODRÍGUEZ ESCANCIANO, S., Hacia un nuevo régimen jurídico del personal al servicio de las Administraciones públicas, Instituto Andaluz de Administración Pública, Sevilla, 2006, pp. 195 ss.; GARCÍA DE ENTERRÍA, E. / FERNÁNDEZ, T.R., Curso de Derecho administrativo I, cit., pp. 445 ss.; MARTÍN - RETORTILLO BAQUER, S., "Reflexiones sobre la 'huida' del Derecho administrativo", en Revista de Administración pública, $\mathrm{n}^{\circ}$ 140, 1996, pp. 25 ss.; MIR PUIGPELAT, O., Globalización, Estado y Derecho. Las transformaciones recientes del Derecho administrativo, Civitas, Madrid, 2004, pp. 160 ss.; RIVERO ORTEGA, R., Administraciones públicas y Derecho privado, Marcial Pons, Madrid, 1998, pp. 13 ss.; SÁNCHEZ MORÓN, M., Derecho administrativo. Parte general, cit., pp. 61-62.

15 Vid. sobre la relevancia de las normas de Derecho privado en la organización y régimen interno de este tipo de entidades, GARCÍA DE ENTERRÍA, E. / FERNÁNDEZ, T.R., pp. 457 ss.; GONZÁLEZ LÓPEZ, J.J., "La huida del Derecho administrativo como factor criminógeno", en Revista de Derecho Penal y Criminología, Vol. 16, 2016, pp. 378 ss.; SÁNCHEZ MORÓN, M., Derecho administrativo. Parte general, cit., pp. 436-438. Se trata de entes con autonomía ejecutiva y cada vez con menor dependencia del Gobierno, incluso en el nombramiento del personal (vid. DESDENTADO AROCA, E., La crisis de identidad del Derecho Administrativo, cit., pp. 133 ss.).

Si bien se ha señalado que esta tendencia puede estar invirtiéndose, especialmente bajo la influencia del Derecho europeo, parece que tal cambio se focaliza esencialmente en el establecimiento de garantías que aseguren la transparencia de todo este tipo de entes, pero sin entrar de lleno en una 
duce inevitablemente a una indeterminación y dispersión de la naturaleza, clases y régimen jurídico de la variada gama de entes instrumentales configurados en el seno de la Administración pública ${ }^{16}$.

Centrándonos específicamente en las sociedades mercantiles públicas, en la jurisprudencia penal encontramos ejemplos de calificación como funcionario público de personas integradas en este tipo de entidades. Así, cabe citar la STS 537/2002, 5-4, que condena por un delito de prevaricación al gerente de una sociedad mercantil municipal. Esta decisión encuentra fundamento en resoluciones anteriores de los Tribunales: "Dice la sentencia de 14 de noviembre de 1995 que la Administración tiene una alternativa para su actuación, o la utilización de formas públicas, o acudir a técnicas privadas, pero que tal opción reviste carácter administrativo y público. 'Nada significa a este respecto la utilización instrumental de formas y técnicas privadas, pues en el fondo existe un núcleo de carácter público, pues aunque tales sociedades municipales están constituidas y revestidas de formas mercantiles y actúen en el tráfico del Derecho privado, siempre precisan una decisión, un acto de carácter administrativo, al que se llega tras un procedimiento administrativo'. Se trata de entes de esta naturaleza integrados en el ámbito municipal, que, aunque calificados de Sociedades Privadas, sujetan su actuación al régimen derivado de las normas administrativas". La anterior argumentación es la que sirve de justificación al Tribunal para considerar funcionario público a efectos penales al gerente de una sociedad mercantil municipal, que como tal ejerce funciones públicas del Ayuntamiento.

modificación sustancial de su régimen y organización: vid. SÁNCHEZ MORÓN, M., "El retorno del Derecho administrativo", en Revista de Administración Pública, $\mathrm{n}^{\circ}$ 206, 2018, pp. 39 ss.

16 Vid. GARCÍA DE ENTERRÍA, E. / FERNÁNDEZ, T.R., Curso, cit., p. 455; FERNÁNDEZ FARRERES, G., "Administraciones instrumentales", en AAVV, Estudios para la reforma de la Administración pública, INAP, Madrid, 2004, p. 341; SÁNCHEZ MORÓN, M., Derecho administrativo. Parte general, cit., pp. 407 ss. 
También se puede citar el caso de la STS 83/2017, 14-2, asimismo con respecto al gerente de una sociedad municipal. La sentencia vuelve a incidir en el hecho de que esta persona "participaba del ejercicio de las funciones públicas, teniendo plenos poderes de disposición sobre las cuentas de la sociedad. Esta interpretación amplia del concepto de funcionario público ha sido la tónica seguida por la Jurisprudencia del Tribunal Supremo, rebasando así las líneas definitorias del concepto administrativo de funcionario, en tanto se atiende de forma primordial a la función desempeñada, alcanzando incluso al personal laboral contratado para el ejercicio de funciones en el ámbito de un organismo público. [...] Es igualmente jurisprudencia de esta Sala, de la que es exponente la Sentencia 186/2012, de 14 de marzo, que el concepto de funcionario público contenido en el artículo 24 del Código Penal, según el cual 'se considerará funcionario público a todo el que por disposición inmediata de la Ley, por elección, o por nombramiento de Autoridad competente participe en el ejercicio de funciones públicas', es un concepto aplicable a efectos penales, como se desprende del mismo precepto, que es diferente del característico del ámbito administrativo, dentro del cual los funcionarios son personas incorporadas a la Administración pública por una relación de servicios profesionales y retribuidos, regulada por el derecho administrativo. Por el contrario, se trata de un concepto más amplio que éste, pues sus elementos son exclusivamente el relativo al origen del nombramiento, que ha de serlo por una de las vías que el artículo 24 enumera, y de otro lado, la participación en funciones públicas, con independencia de otros requisitos referidos a la incorporación formal a la Administración Pública o relativos a la temporalidad o permanencia en el cargo (STS n ${ }^{\circ}$ 1292/2000, de 10 de julio; STS n ${ }^{\circ}$ 68/2003, de 27 de enero; STS n 333/2003, de 28 de febrero y STS n $663 / 2005$, de 23 de mayo), e incluso de la clase o tipo de función pública, y aquella participación en las funciones públicas puede serlo -como expresa la STS 22-4-2003- tanto en las del Estado, entidades locales o comunidades autonómicas e incluso en los de la llamada administración institucional que tiene lugar 
cuando una entidad pública adopta una forma independiente, incluso con personalidad jurídica propia, en ocasiones de sociedad mercantil, con el fin de conseguir un más ágil y eficaz funcionamiento, de modo que cualquier actuación de estas entidades donde existe un interés público responde a este concepto amplio de función pública. Y en lo que se refiere al acceso al ejercicio de tales funciones públicas nada importan en este campo ni los requisitos de elección para el ingreso, en la categoría por modesta que fuera, ni el sistema de retribución, ni el estatuto legal y reglamentario, ni el sistema de provisión, ni aún la estabilidad o temporalidad (STS 4.12.2001). [...] Se trata, en definitiva, como señalan tanto la doctrina como la jurisprudencia (SSTS 22.1.2003 y 19.12.2000) de un concepto "nutrido de ideas funcionales de raíz jurídico-política, acorde con un planteamiento político-criminal que exige, por la lógica de la protección de determinados bienes jurídicos, atribuir la condición de funcionario en atención a la funciones y fines propios del derecho penal y que, sólo eventualmente coincide con los criterios del derecho administrativo" "17.

Otro caso en la misma línea lo encontramos en la STS 421/2014, 16-5, donde se consideró funcionario público al gerente de la entidad Mercasevilla, S.A., que según el Tribunal se trata de una empresa mixta del sector público local que ejerce una indudable función pública, al estar encargada de la prestación de un servicio público de competencia local (servicios de mercados centrales de mayoristas y servicio de matadero), con capital mayoritariamente público ${ }^{18}$. Aún más, el Tribunal

17 Esta sentencia, de hecho, reitera los argumentos de la STS 149/2015, 11-3 y de la STS 421/2014, 16-5.

18 Según la sentencia, "el socio mayoritario de Mercasevilla es el Ayuntamiento de Sevilla, con un $51 \%$ de las acciones, y que también es socio de la misma MERCASA, empresa pública de la Administración del Estado, cuyos accionistas son la Sociedad Estatal de Participaciones Industriales (SEPI) y el Ministerio de Agricultura, Alimentación y Medio Ambiente a través del Fondo Español de Garantía Agraria (FEGA), siendo su capital íntegramente del Estado, la cual detenta el $48 \%$ del capital social. En vista de lo cual, concluye el Tribunal del Jurado que el nombramiento de Director Gerente 
efectúa las mismas consideraciones en relación con la Fundación Socio-Asistencial Mercasevilla, que reviste la condición de fundación del sector público local ${ }^{19}$, teniendo entre sus fines "contribuir a la mejora de la prestación del servicio público de mercado mayorista alimentario, compartiendo la función de Mercasevilla S.A. De modo que, no obstante ser una realidad que formalmente Mercasevilla y la Fundación son dos entidades diferentes, desde el punto de vista legal y práctico la Fundación

de Mercasevilla es realizado por los socios mayoritarios, por cuanto, según los Estatutos de la sociedad mixta aprobados por el Ayuntamiento de Sevilla en el expediente de municipalización en su sesión de 8 de mayo de 1971, ratificados por el Ministerio de la Gobernación en resolución de fecha 19 de mayo siguiente, para dicho nombramiento es necesario que asistan a la Junta General cuatro quintas partes del capital desembolsado, y en segunda convocatoria las tres cuartas partes de dicho capital, lo que implica, a la vista de la distribución del capital social de la entidad examinada, que los representantes del Ayuntamiento y de la Sociedad pública Mercasa son los encargados del nombramiento, trasladando a la Junta las instrucciones de la autoridad pública titular de los intereses que defienden [...]

Mercasevilla, S.A., gestiona un servicio de genuina competencia municipal mediante concesión administrativa en régimen de monopolio: los servicios de Mercados Centrales y Matadero, que constituyen materia propia de la competencia municipal, e incluso se integran entre los que revisten carácter de obligación mínima a tenor de lo previsto en los arts. 25 y 26 de la Ley 7/1985, de 2 de abril, Reguladora de las Bases del Régimen Local, figurando entre los que pueden ser municipalizados en monopolio. La personalidad jurídica de la empresa ha de considerarse conferida por el Ayuntamiento a través del expediente de municipalización. En dicho expediente, sancionado por el entonces Ministro de la Gobernación, se contienen las bases por las que ha de regirse la empresa, que son de obligado acatamiento para los representantes del capital privado, que representan el 0,2\%. La empresa mixta Mercasevilla tiene, pues, carácter público, y alberga como finalidad la prestación de un servicio público".

19 Indica la sentencia que "la constitución de la Fundación Socio-Asistencial Mercasevilla fue aprobada por la Junta General Extraordinaria de Mercasevilla S.A. en sesión celebrada el día 21 de junio de 2004, siendo dotada con la suma de 30.000 euros que aportaría la entidad Mercasevilla S.A., en orden a su composición. El art. 12 de los Estatutos de la Fundación establece que el Patronato estará compuesto por un mínimo de tres y un máximo de cinco patrones, formando parte en todo caso del Patronato el Presidente y el Vicepresidente Segundo del Consejo de Administración de Mercasevilla, así como el Director General de Mercasevilla". 
Socio-Asistencial Mercasevilla no es más que un instrumento jurídico creado por la Empresa Mercasevilla como medio para desarrollar proyectos que contribuyan a la mejora del servicio público de mercado mayorista alimentario".

Asimismo, en la STS 166/2014, 28-2, se consideró funcionario público al gerente de otra sociedad mercantil estatal, argumentando que "la citada empresa participaba en el ejercicio de funciones públicas. Pues sus funciones consistían en la preparación de la venta de una empresa pública, garantizando, a través de una sociedad estatal, que la privatización se realizaba con respeto a los intereses generales. Está admitido que el Estado puede actuar mediante sociedades estatales revistiendo formas jurídico privadas, por considerarse que de esa manera se gestiona más adecuada y eficazmente los intereses generales, situación que se presenta en este caso, que para gestionar intereses generales se buscó la creación de una empresa con la forma de sociedad anónima. El objeto social de esta empresa es 'la construcción, promoción, venta, arrendamiento o explotación de cualquier forma de edificios e inmuebles destinados a su utilización por los servicios de la Administración Pública y actividades inmobiliarias accesorias con los fines señalados'. Y, la misión concreta de la citada empresa era 'la privatización de Intelhorce', lo que implica gestionar intereses generales en virtud de una decisión política del Ministerio de Economía y Hacienda. Por lo que se refiere al título, es decir el modo de acceso al desempeño de la función, consta en el relato fáctico que la Dirección General del Patrimonio, como accionista único de Improasa, designaba a la totalidad del Consejo de Administración, incluido el Presidente, por lo que es claro que el acusado participaba del ejercicio de funciones públicas por nombramiento de autoridad competente, requisitos que son los exigidos por el art. 24 del CP 95 (antes 119 CP 73) para ostentar la condición de funcionario a efectos penales".

En esta línea se manifestaba ya la STS 1590/2003, 224, con respecto a la consideración de funcionario público del presidente de esta última sociedad mercantil estatal (Improasa): 
según la sentencia, tal concepto "incluye, por tanto, a los empleados de concesionarios de servicios públicos (STS de 19 de diciembre de 1999); gestores de empresas que prestan servicios públicos cuyo patrimonio se integra en el de una Administración Pública (STS de 29 de abril de 1997); así como a las entidades estatales reguladas en los arts. 6.2 LGP, pues al ser éstas parte del sector público y tener asignada la prestación de un servicio público el perjuicio causado con su administración ilícita no puede dejar de gravar los Presupuestos Generales del Estado (STS de 13 de noviembre de 2002). Resulta evidente por todo ello que una conclusión distinta no puede mantenerse en el caso de la empresa Inmobiliaria de Promociones y Arriendos, SA (Improasa), Sociedad Estatal cuyo director-el acusado Francofue designado a través de la Dirección General del Patrimonio del Estado".

En suma, resulta evidente que hace ya largo tiempo viene desarrollándose un proceso de dispersión y diversificación de la forma de ejercicio de las actividades públicas, que pasan a ser prestadas por diferentes entes jurídicos instrumentales, dependientes en diversa medida de la Administración y con una mayor o menor autonomía en su régimen de funcionamiento, o directamente por empresas privadas, si bien bajo diferentes tipos de control por parte de las Administraciones públicas ${ }^{20}$. Sin embargo, como acabamos de ver, el establecimiento de nuevas formas de organización de la Administración no ha de ser óbice para identificar si estamos ante el ejercicio real de una función pública. Las sentencias anteriores realmente proceden a integrar a los dirigentes de diversas sociedades mercantiles públicas en el concepto de funcionario público a efectos penales, del artículo 24 del Código Penal; si bien este precepto combina un elemento material (participación en el ejercicio de funciones públicas) y uno formal (existencia de una designación legal, por elección o por nombramiento de autoridad competente), es evidente que

20 Vid. GARCÍA DE ENTERRÍA, E. / FERNÁNDEZ, T.R., Curso, cit., pp. 441 ss.; FERNÁNDEZ DOMÍNGUEZ, J.J. / RODRÍGUEZ ESCANCIANO, S., Hacia un nuevo régimen jurídico, cit., pp. 202-203. 
este último elemento no se centra en formalismos rígidos, sino que su objetivo es situar la esencia de este concepto en el ejercicio real de funciones públicas, independientemente de la clase de vínculo formal existente con la Administración ${ }^{21}$. En esta línea, también el concepto de cargos públicos propio de las penas de inhabilitación ha de estar basado en esta interpretación material, considerándose que ejercen un cargo de tal naturaleza quienes participan en el ejercicio de funciones públicas, bajo alguna cobertura formal que muestre la existencia de una designación y conexión con la Administración pública.

Además del supuesto de las sociedades mercantiles públicas, es interesante mencionar también el caso de las corporaciones. Las corporaciones se definen como grupos de personas organizadas con un interés común, con la participación de todas ellas en la administración del ente ${ }^{22}$. El problema aquí se plantea en relación con las corporaciones que constituyen grupos de personas asociadas en torno a una finalidad específica, cuya unión se basa en alguna condición relacionada con el objetivo que las guía: puede ser una cualidad profesional (Colegios profesionales), la utilización de un determinado servicio público (Comunidades de usuarios de aguas $)^{23}$, la condición de comerciante o empresario (Cámaras de comercio) ${ }^{24}$, la condición de ciudadano

21 Vid. más en extensión sobre el concepto de funcionario público a efectos penales, infra, al final de este mismo epígrafe.

22 Cfr. GARCÍA DE ENTERRÍA, E. / FERNÁNDEZ, T.R., Curso, cit., p. 424; GARRIDO FALLA, F. / PALOMAR OLMEDA, A. / LOSADA GONZÁLEZ, H., Tratado de Derecho administrativo. Parte general, Tecnos, Madrid, 2010, pp. 435-436; PARADA VÁZQUEZ, J.R., Derecho administrativo I, Ediciones Académicas, Madrid, 2017, pp. 363 ss.

23 Según SÁNCHEZ MORÓN, M., Derecho administrativo. Parte general, cit., p. 427, tienen como objetivo ordenar el aprovechamiento común de las aguas que corresponden a un conjunto de usuarios, provenientes de una misma toma o concesión. En la toma de decisiones sobre el aprovechamiento del agua, como bien público, se aprecia el ejercicio de auténticas funciones públicas.

24 Vid. PARADA VÁZQUEZ, J.R., Derecho administrativo I, cit., pp. 378 ss. Siguiendo a SÁNCHEZ MORÓN, M., Derecho administrativo. Parte general, cit., pp. 426-427, se trata de entidades constituidas para promover y 
afectado por la ejecución de un plan de urbanismo elaborado por la Administración (Juntas de compensación, por ejemplo) ${ }^{25}$, etc.

El debate en torno a estas corporaciones se centra en decidir si son auténticas corporaciones de Derecho público o si constituyen entidades corporativas de naturaleza privada. Tradicionalmente se ha efectuado la distinción entre corporaciones públicas y privadas en función de las condiciones que determinan su constitución. Hay que partir del dato de que las corporaciones privadas surgen por libre voluntad de sus miembros, y las públicas por resolución de la ley o de la Administración. Sin embargo, debe tenerse en cuenta que existen ciertas corporaciones que, si bien se constituyen necesariamente por disposición legal o resolución administrativa, están dirigidas a la consecución de objetivos claramente privados; en consecuencia, el interés público en la existencia de tal organización no va a implicar automáticamente que ésta ejerza auténticas funciones o actividades públicas. Lo que determina que la Administración o la ley impongan coactivamente su constitución, es el interés público y el objetivo de que tales actividades privadas se desarrollen de forma correcta; por esto mismo se atribuye a tales entes el ejercicio de ciertas facultades de administración y organización de sus propios miembros, tal y como si existiera una auténtica potestad administrativa. Esto ocurre, por ejemplo, con los Colegios profesionales, corporaciones a las que la ley atribuye la ordenación y la representación de los intereses de determinadas profesiones ${ }^{26}$ : es obligatorio, por ley, que determinados profesionales se

defender determinados intereses generales. Vid. sobre su naturaleza jurídica y funciones de carácter público - administrativo, CABEZAS HERNÁNDEZ, M.T., Las Cámaras de comercio, industria y navegación de España: naturaleza jurídica y funciones, Atelier, Barcelona, 2002, pp. 546 ss.

25 En este caso, existe una participación en el ejercicio de funciones públicas debido a que estas entidades tienen la facultad de asignar derechos urbanísticos o de imponer cargas económicas para cumplir con los deberes legales que puedan derivarse de la urbanización; vid. SÁNCHEZ MORÓN, M., Derecho administrativo. Parte general, cit., p. 428.

26 Cfr. PARADA VÁZQUEZ, J.R., Derecho administrativo I, cit., p. 375; SÁNCHEZ MORÓN, M., Derecho administrativo. Parte general, cit., pp. 423 ss. 
agrupen en estos entes corporativos, pero esto no significa que las funciones del Colegio sean de naturaleza estrictamente pública; en su ámbito podemos observar, como se acaba de decir, la existencia de unas ciertas facultades de organización y control, por ejemplo en la existencia de unas infracciones y sanciones disciplinarias para los miembros del Colegio ${ }^{27}$.

En suma, estamos ante supuestos en que aparece una cierta mezcla entre el interés público y privado, y por esto mismo no se ha ofrecido una respuesta categórica al interrogante de si constituyen un ente público y ejercen funciones propias de la Administración pública ${ }^{28}$. Se trata simplemente de reconocer que existe un interés público en la existencia de la corporación,

27 Vid. GARCÍA DE ENTERRÍA, E. / FERNÁNDEZ, T.R., Curso, cit., pp. 434 ss. La adscripción obligatoria a estas corporaciones, que quiebra la libertad negativa de asociación, se ha justificado, tanto por la doctrina como por el propio Tribunal Constitucional, por el interés público que justifica la ordenación de una concreta actividad y por las funciones públicas de control que se atribuyen a determinados miembros de la corporación; no obstante, debe señalarse que tal justificación no se ha admitido en relación con todas las clases de corporaciones. Vid. GARRIDO FALLA, F. / PALOMAR OLMEDA, A. / LOSADA GONZÁLEZ, H., Tratado, cit., pp. 436-437; FERNÁNDEZ FARRERES, G., "Corporaciones de Derecho público", AAVV, Estudios para la reforma de la Administración pública, INAP, Madrid, 2004, p. 366; LÓPEZ GONZÁLEZ, J.L., Los Colegios profesionales como corporaciones de Derecho público: un estudio en clave constitucional, Nomos, Valencia, 2001, pp. 127 ss.; SALOM PARETS, A., Los Colegios profesionales, Atelier, Barcelona, 2007, pp. 94 ss.; SÁNCHEZ MORÓN, M., Derecho administrativo. Parte general, cit., pp. 425-426.

28 Como manifiesta PARADA VÁZQUEZ, J.R., Derecho administrativo I, cit., p. 374, se aprecia una mezcla entre lo público y lo privado que determina la existencia de un "régimen jurídico mixto de contornos no siempre bien delimitados". Por su parte, SÁNCHEZ MORÓN, M., Derecho administrativo. Parte general, cit., p. 423, señala que estamos ante "una fórmula más de colaboración entre Administración y sociedad, de mixtura entre público y privado". GARRIDO FALLA, F. / PALOMAR OLMEDA, A. / LOSADA GONZÁLEZ, H., Tratado, cit., p. 435, citan jurisprudencia constitucional en la que expresamente se reconoce la polémica existente sobre la naturaleza de estas entidades, asumiendo que cabe atribuirles un carácter mixto entre lo público y lo privado. SALOM PARETS, A., Los Colegios, cit., pp. 82 ss., considera a los Colegios profesionales como auténtica Administración pública. 
generalmente con el objetivo de regular una actividad que repercute en la comunidad social; aunque los miembros de tales entidades corporativas persigan fines privados, hay un interés general en que sus actividades se desarrollen en un marco determinado, y por ello existen unas ciertas facultades de ordenación y disciplina, propias de la Administración pública, en el marco de la entidad corporativa. De hecho, la propia jurisprudencia ha destacado que, partiendo de la naturaleza eminentemente privada de tales entidades, también tienen reconocido por ley o por resolución administrativa el ejercicio de algunas funciones públicas, como agentes descentralizados de la Administración a tales efectos ${ }^{29}$.

Así, teniendo presente esta naturaleza ambivalente de tales corporaciones cabe concluir, a los efectos que aquí interesan, que con carácter general no constituye función ni cargo público la mera pertenencia a estas corporaciones, puesto que sus asociados se integran en ellas con el fin de satisfacer fines privados $\mathrm{y}$ de ejercer actividades de esta naturaleza ${ }^{30}$.

No obstante, puede efectuarse una salvedad en relación con aquellos sujetos que, siendo parte de uno de estos entes corporativos, tienen facultades de organización y disciplina del ente porque así lo determina la ley o la propia Administración. Como se ha visto, en este punto se manifiesta el verdadero interés pú-

29 Vid. GARCÍA DE ENTERRÍA, E. / FERNÁNDEZ, T.R., Curso, cit., pp. 437-438. Vid. también en esta línea PARADA VÁZQUEZ, J.R., Derecho administrativo I, cit., pp. 374-375; SALOM PARETS, A., Los Colegios, cit., pp. 83 ss.; vid. también SÁNCHEZ MORÓN, M., Derecho administrativo. Parte general, cit., pp. 423 ss., señalando que la ley atribuye a las corporaciones el ejercicio de determinadas funciones administrativas. Vid. asimismo FERNÁNDEZ FARRERES, G., "Corporaciones”, cit., p. 371, poniendo de relieve que la función pública propia de los Colegios profesionales consiste en la ordenación del ejercicio de la profesión, la cual implica la existencia de potestades disciplinarias y de control.

30 GARRIDO FALLA, F. / PALOMAR OLMEDA, A. / LOSADA GONZÁLEZ, H., Tratado, p. 436, señalan que los miembros de las corporaciones no tienen la condición de funcionario público ni de cargo público, citando jurisprudencia constitucional en relación con el concepto de cargo público. 
blico en la constitución de la entidad corporativa: se pretende regular el correcto ejercicio de una determinada actividad, porque razones objetivas justifican la necesidad de su control. Así, por ejemplo, los Colegios profesionales tienen facultad disciplinaria sobre sus miembros, y regulan algunas cuestiones como la realización de determinados informes, la fijación de los turnos de guardia, etc.; las Comunidades de usuarios de agua regulan la gestión del uso del agua y las sanciones que se impondrán por el incumplimiento de tales normas, etc. ${ }^{31}$. Por consiguiente, aquellos miembros de la corporación que tengan encomendado el ejercicio de estas funciones de organización y disciplina, que son auténticas funciones públicas en cuanto encomendadas por la ley o por la propia Administración, sí pueden considerarse como ostentadores de un cargo público. De todos modos, debe puntualizarse que, si se les impone una pena de inhabilitación, solo perderían estas concretas funciones, pero no su condición de simples miembros de la corporación, pues el hecho de ser integrante de uno de estos entes se vincula únicamente con el ejercicio de una actividad privada, que como tal no puede quedar abarcada por la prohibición de ejercicio de una función pública.

De hecho, en esta línea podemos encontrar diversas resoluciones judiciales. Cabe citar, por ejemplo, la STS 874/2006, 18-9, que considera funcionario público al patrón mayor de una Cofradía de pescadores y mariscadores. Según el Tribunal, "la Cofradía desarrolla sus actividades como entidad pública colaboradora de la Administración en el sector pesquero y al servicio del interés general en este ámbito y sus fines vienen marcados por una indiscutible proyección pública (se excluye expresamente la finalidad lucrativa de su actuación) relacionada con la protección de los bancos marisqueros y con la ayuda, protección y control de la actividad pesquera".

Puede ponerse asimismo el ejemplo de la STS 789/2001, 10-5: "En su sentencia de 10-10-1997 esta Sala ha considerado que los miembros de la Junta de Gobierno del Colegio de

31 Cfr. GARCÍA DE ENTERRÍA, E. / FERNÁNDEZ, T.R., Curso de Derecho administrativo I, cit., p. 435. 
Diplomados en Enfermería de Barcelona ostentan la calidad de funcionarios públicos. Dicho Colegio es una corporación de derecho público que ejerce funciones públicas pues tiene competencias de inspección administrativa y sus actos son recurribles ante el orden jurisdiccional contencioso-administrativo. Consecuentemente, en tanto el recurrente formaba parte como Secretario de la Junta de Gobierno de dicho Colegio e intervino en los hechos como tal, habiendo asumido la custodia de los votos emitidos por correo, ejercía una función pública consistente en dicha custodia de los documentos destinados a la elección de los miembros de la Junta de Gobierno del Colegio".

Finalmente, cabe citar más brevemente otros ejemplos: la STS 1233/1997, 10-10, que considera funcionario público a efectos penales al presidente del Colegio oficial de Diplomados en enfermería de Barcelona ${ }^{32}$, puesto que en su calidad de presidente desempeñaba funciones públicas consistentes en la representación de una corporación de Derecho público (el Colegio profesional), que está sometida al control e inspección de la Administración y cuyos acuerdos son recurribles en la jurisdicción contencioso -administrativa; la STS 789/2001, 10-5, en relación con un miembro de la Junta de Gobierno de un Colegio de Diplomados en enfermería; y la SAP La Rioja 510/2005, 15-12, sobre el presidente del Colegio Oficial de agentes comerciales. Asimismo, en idéntico sentido se manifiesta la STS 1104/1998, 3-10, considerando que el patrón mayor de una Cofradía de pescadores desempeña funciones públicas, teniendo en cuenta que es uno de los órganos rectores de estas corporaciones de Derecho público, con auténtica potestad sancionadora y cuyas decisiones son susceptibles de ser recurridas en vía contencioso- administrativa ${ }^{33}$.

32 Cfr. LÓPEZ MARTÍN DE LA VEGA, R., La huelga de funcionarios públicos y el Código penal, Bomarzo, Albacete, 2005, pp. 262-263; MIR PUIG, C., Los delitos contra la Administración pública en el nuevo Código penal, Bosch, Barcelona, 2000, p. 26.

33 Vid. este ejemplo en LÓPEZ MARTÍN DE LA VEGA, R., La huelga, cit., p. 264. En cambio, manifiesta este autor que el Tribunal Supremo no ha 
En suma, al igual que en el caso de las sociedades mercantiles públicas, la jurisprudencia también ha considerado funcionario público a quienes ostentan las funciones de organización y disciplina en el ámbito de esta clase de corporaciones. Por consiguiente, a efectos de la aplicación de la pena de inhabilitación, puede considerarse que estas personas ejercen un cargo público, ya que desempeñan auténticas funciones públicas en cuanto encomendadas por la ley o por la propia Administración. Por el contrario, no constituye cargo público la mera pertenencia a la corporación, ni tampoco debe considerarse cargo público la colaboración externa, por parte de personas ajenas a la corporación, en el ejercicio de las funciones de organización y control propias de estos entes. En esta última línea, por ejemplo, puede atenderse a lo manifestado en la STS 383/2018, 25-7, según la cual un sujeto contratado como vigilante de una Cofradía de pescadores no puede ser considerado funcionario público: "Las Cofradías solo desarrollan funciones de carácter administrativo cuando actúan como órganos de consulta y colaboración con la Administración - art. 1 del Decreto 8/2014, de 16 de enero, por el que se regulan las cofradías de Pescadores en Galicia y sus federaciones-, lo que no es el caso en relación a tales contratados. El art. 2 de tal Decreto referido al régimen jurídico de tales corporaciones resalta el carácter no administrativo del resto de sus actuaciones, las no estrictamente vinculadas con esa actividad consultiva y auxilio a la Administración. Entre ellas hay

considerado funcionario público al empleado de una Cámara agraria con base, por una parte, en que las Cámaras son entidades privadas, y por otra parte, en que quienes actúan como mandatarios de los miembros de tales corporaciones no están ejerciendo funciones públicas.

Efectivamente, las cofradías son corporaciones de Derecho público; véase como ejemplo el art. 1 de la Ley 9/1993, 8 julio, de cofradías de pescadores de Galicia. Vid. asimismo REBOLLO PUIG, M. / FALCÓN Y TELLA, R. / LÓPEZ BENÍTEZ, M., Naturaleza y régimen jurídico de las cofradias de pescadores, Universidad de Córdoba, 1996, pp. 29 ss.: si bien se caracterizan por la libertad de decisión de formar parte de la propia corporación, son de "Derecho público" porque son los poderes públicos quienes deciden su creación, configuración esencial, extinción y también finalidades, que son de interés público. 
que ubicar todo lo referido a la contratación de personal para tareas varias entre ellas la protección de sus intereses corporativos con un sistema de vigilantes (guardapescas) privados. Los guardapescas marítimos colaboran con el Servicio de Guardacostas de Galicia para fortalecer las actividades de vigilancia e inspección; pero eso no les otorga la condición ni de agentes de la autoridad, ni de funcionarios públicos. No pierden su carácter de particulares ni a efectos de su posible tutela penal (como destaca la defensa en su impugnación al recurso); ni para alcanzar la idoneidad para ser sujetos activos de delitos especiales especificados por la condición de autoridad o funcionario público. $\mathrm{Su}$ contratación por la Cofradía de pescadores los hace trabajadores al servicio de aquélla; pero no constituye un nombramiento para ejercer funciones públicas. Continúan siendo particulares que colaboran con quienes sí desempañan directamente funciones públicas (guardacostas)".

Otro supuesto en el que puede resultar complejo caracterizar la naturaleza de determinadas actividades, es el referido a aquellas personas que tienen una relación con la Administración en virtud de determinados contratos regulados en la Ley de Contratos del Sector Público (Ley 9/2017, 8-11). Son relevantes a los efectos que aquí interesan los contratos administrativos, que atendiendo a los artículos 12 y 25 de la Ley pueden ser contratos de obras, suministros, servicios, concesión de obra y concesión de servicios. La amplia y flexible configuración legal de estos contratos permite emplear esta técnica para un conjunto muy variado de supuestos; en esta línea, es interesante analizar hasta qué punto los sujetos vinculados con la Administración por estos contratos están participando en el ejercicio de funciones públicas.

Si examinamos la enumeración ofrecida de contratos administrativos, vemos que se centran en la realización de actividades propias de la Administración, tales como obras públicas, suministros, y muy variados tipos de servicios públicos. Entre ellos, suscitan aquí especial interés los contratos de servicios y 
de concesión de servicios, puesto que suponen una participación más directa y en muchos casos con cierta permanencia en el desarrollo y prestación de un servicio público. Con este tipo de contratos se deja en manos privadas la prestación de servicios esenciales para la comunidad social ${ }^{34}$.

En fin, se aprecia que la contratación administrativa es un amplio campo en el que tiene cabida la realización de actividades que podrían ser objeto de un contrato laboral con la Administración, o que esta última podría realizar con sus propios medios, pero que pueden encauzarse a través de esta vía de la celebración de contratos administrativos. Incluso el límite establecido en la legislación, que implica la imposibilidad de celebrar contratos en relación con servicios que conlleven ejercicio de autoridad inherente a los poderes públicos (artículo 17 de la Ley), es de dudosa operatividad: se trata de una expresión en cierto modo indeterminada, y se aprecia la falta de precisión legal de los servicios a los que es inherente este ejercicio de autoridad, lo cual puede redundar en el relativismo y la indefinición a la hora de concretar qué tipo de actividades no pueden ser ejecutadas a través de la vía de los contratos administrativos ${ }^{35}$. En

34 Cabe citar los ejemplos del abastecimiento de agua o la recogida de residuos, e incluso otros ámbitos como los sanitarios y asistenciales; vid. por ejemplo sobre estos contratos FERNÁNDEZ ASTUDILLO, J.M., El nuevo régimen de contratación pública, Bosch Wolters Kluwer, Madrid, 2018, pp. 174 ss.; MANENT ALONSO, L., "Contrato de concesión de servicios", en RECUERDA GIRELA, M.A. (Dir.), Comentarios a la nueva Ley de contratos del sector público, Civitas Thomson Reuters, Cizur Menor, 2018, pp. 160-167; NÚÑEZ SÁNCHEZ, F., "Contrato de servicios”, en RECUERDA GIRELA, M.A. (Dir.), Comentarios a la nueva Ley de contratos del sector público, op. cit., pp. 173-177; VALCÁRCEL FERNÁNDEZ, P., "La delimitación de los tipos contractuales", en GIMENO FELIÚ, J.M., Estudio sistemático de la Ley de Contratos del Sector Público, Aranzadi Thomson Reuters, Cizur Menor, 2018, pp. 431 ss. y 463 ss.

35 Vid. VALCÁRCEL FERNÁNDEZ, P., "La delimitación de los tipos contractuales", cit., pp. 467-468. Como manifiesta SÁNCHEZ MORÓN, M., Derecho administrativo. Parte general, cit., p. 600, esta previsión legal no ha llegado a impedir que empresas privadas puedan ser contratadas, por ejemplo, para funciones de vigilancia y seguridad, núcleo esencial de los poderes del Estado. 
suma, la utilización de determinados contratos administrativos plantea la cuestión de que el particular va a gestionar, con una determinada permanencia temporal, un servicio público ${ }^{36}$ cuya titularidad corresponde a la Administración. De hecho, si bien tradicionalmente los servicios públicos eran gestionados de forma directa por la propia Administración, con el paso del tiempo se ha ido haciendo cada vez más frecuente la gestión indirecta de estos servicios, a través de este tipo de contratos administrativos $^{37}$. Esto sin duda tendrá consecuencias muy importantes a efectos de la pena de inhabilitación, puesto que un contratado laboral o un funcionario es un empleado público, y por lo tanto su actividad se ve afectada por la condena a la inhabilitación, y en cambio un sujeto que presta un servicio a la Administración en virtud de un contrato administrativo quedaría en principio inmune a los efectos de esta pena ${ }^{38}$.

36 Vid. PARADA VÁZQUEZ, J.R., Derecho administrativo II, Ediciones Académicas, Madrid, 2018, pp. 156 ss.; vid. sobre la noción de servicio público como satisfacción de una necesidad de interés general por parte de la Administración, ARIÑO ORTIZ, G., Principios de Derecho público económico. Modelo de Estado, gestión pública, regulación económica, Comares, Granada, 2004, pp. 544 y 548.

37 Como manifiesta PARADA VÁZQUEZ, J.R., ibídem, en la actualidad concurren la gestión directa de la Administración y las empresas privadas en la satisfacción de las necesidades de interés general; vid. también SÁNCHEZ MORÓN, M., Derecho administrativo. Parte general, cit., pp. 587 ss. Vid. sobre esta evolución del régimen de prestación de los servicios públicos, ARIÑO ORTIZ, G., Principios, cit., pp. 599 ss.; LÓPEZ CANDELA, J.E., Sobre la necesidad de un concepto de servicio público, CGPJ, Madrid, 2004, pp. 36 ss.

38 En cualquier caso, hay que tener presente la vigencia del artículo 71 de la Ley de Contratos del Sector Público, cuyo apartado 1.a) impone la prohibición de contratar con el sector público a las personas que hayan sido condenadas "mediante sentencia firme por delitos de terrorismo, constitución o integración de una organización o grupo criminal, asociación ilícita, financiación ilegal de los partidos políticos, trata de seres humanos, corrupción en los negocios, tráfico de influencias, cohecho, fraudes, delitos contra la Hacienda Pública y la Seguridad Social, delitos contra los derechos de los trabajadores, prevaricación, malversación, negociaciones prohibidas a los funcionarios, blanqueo de capitales, delitos relativos a la ordenación del territorio y el urbanismo, la protección del patrimonio histórico y el medio 
De nuevo aquí, al igual que en relación con los dos anteriores casos relativos a las sociedades mercantiles públicas y las corporaciones, nos encontramos con resoluciones de nuestros Tribunales que han calificado de funcionario público a efectos penales a personas que desarrollaban diversas funciones en el marco de un contrato administrativo.

Así, por ejemplo, cabe comenzar con la STS 186/2012, 14-3, en la cual se consideraba funcionario público, a efectos de una condena por cohecho, a una persona que había suscrito un contrato administrativo de arrendamiento de servicios con la Administración municipal, como profesional dedicado a la vigilancia y control de zonas rurales.

La sentencia, citando jurisprudencia anterior, comienza indicando que, "como dice la STS 1608/2005 de 12-12, el concepto de funcionario público es propio del orden penal y no vicario del derecho administrativo, ello tiene por consecuencia que dicho concepto es más amplio en el orden penal, de suerte que abarca e incluye a todo aquél que ... por disposición inmediata de la Ley, o por elección o por nombramiento de autoridad competente participe en el ejercicio de funciones públicas..., art. $24.2^{\circ}$ y 2 , el factor que colorea la definición de funcionario es precisamente, la participación en funciones públicas. Por ello se deriva que a los efectos penales, tan funcionario es el titular, o de carrera como el interino o contratado temporalmente, ya que lo relevante es que dicha persona esté al servicio de entes públicos, con sometimiento de su actividad al control del derecho administrativo, aunque carezca de las notas de incorporación definitivas ni por tanto de permanencia (SSTS 1292/2000, de 10-7; 4.12.2002; 1544/2004, de 23.1)".

ambiente, o a la pena de inhabilitación especial para el ejercicio de profesión, oficio, industria o comercio. La prohibición de contratar alcanzará a las personas jurídicas que sean declaradas penalmente responsables, y a aquellas cuyos administradores o representantes, lo sean de hecho o de derecho, vigente su cargo o representación y hasta su cese, se encontraran en la situación mencionada en este apartado". 
La sentencia continúa precisando que "en cuanto al concepto de función pública, la doctrina ha utilizado diversos criterios para su identificación. Desde un punto de vista formal se ha entendido que se calificarán como funciones públicas las actividades de la Administración sujetas al Derecho público; teniendo en cuenta las finalidades con las que se ejecuta la actividad, se ha sostenido también que serán funciones públicas las orientadas al interés colectivo o al bien común, realizadas por órganos públicos. La jurisprudencia ha empleado un criterio de gran amplitud y en general ha entendido que son funciones públicas las realizadas por entes públicos, con sometimiento al Derecho Público y desarrolladas con la pretensión de satisfacer intereses públicos. [...] En la STS no 876/2006, de 6 de noviembre, que confirmó la sentencia por un delito de atentado del que fue víctima el Director- Conservador de un Parque Natural, designado por el Conseller de Medio Ambiente y dependiente de la Dirección General de Conservación del Medio Natural, se afirmó que 'la jurisprudencia exige, para la determinación de la función pública, la existencia de un órgano estatal que realiza un acto que consigue finalidades públicas, y no privadas, y dirigidas al bien común. Desde esa perspectiva, la Jurisprudencia ha considerado como funciones públicas, las que afectan a la cultura, a la Hacienda pública, a la enseñanza, justicia, comunicaciones, agricultura, abastecimientos, vivienda, etc., y, consecuentemente, funcionarios públicos, a quienes desarrollan funciones del Estado, en un sentido amplio. Para una correcta determinación del carácter público de la actuación ha de partirse, necesariamente, de la concurrencia de una finalidad dirigida a satisfacer los intereses generales, el criterio teleológico al que hemos hecho referencia con anterioridad, esto es, a las potestades de la administración, legislativa, jurisdiccional y ejecutiva, y dentro de éstas las dirigidas a la satisfacción del bien común, enseñanza, justicia, hacienda, fomento, comunicaciones, seguridad, agricultura, sanidad, abastecimientos, etc. Criterio que ha de ser delimitado, a su vez, por el requisito subjetivo, en cuya virtud el órgano del que emane sea público, y otro objetivo, por 
el que se exige que la actividad sea regida por normas de carácter público, aunque la relación entre el sujeto que la realiza y el órgano pueda ser regulada por normas no públicas'."

Tras esta argumentación, la sentencia concluye que el profesional que ha concluido un contrato administrativo con el Ayuntamiento puede ser considerado funcionario público a efectos penales, "dado que el servicio municipal que le era encomendado en virtud del contrato administrativo suscrito con el Ayuntamiento, estaba orientado a la satisfacción de un interés público colectivo, participando y correspondiente al concepto amplio de función pública"39.

39 En esta línea puede citarse un buen número de resoluciones judiciales, así por ejemplo la STS 663/2005, 23-5, en relación con un arquitecto técnico vinculado con el Ayuntamiento por contrato temporal: "El art. $24 \mathrm{CP}$. da un concepto de funcionarios públicos más amplio que el que utiliza el derecho administrativo [...], al no requerirse ni la nota de incorporación ni la de permanencia a través de su incorporación a las plantillas de funcionario, y así la jurisprudencia ha tenido que aclarar que el CP da 'un concepto de funcionario público propio y privativo de este campo jurídico, y que no se trata, pues, de una norma en blanco que pueda remitir la definición a otras disposiciones, del Derecho Administrativo o Laboral, con las que puede no concordar' (STS 2208/93 de 11.10). Así pues, 'la cualidad de funcionario a efectos penales no puede subordinarse, ni hacerse depender de su vinculación o calificación administrativa, ni de las definiciones contenidas en las normas reguladoras de su relación con la Administración Pública, sino que ha de atenderse al art. 119 del Código Penal, que sólo hace depender tal cualidad del hecho concreto y real que una persona se halle participando más o menos permanente o temporalmente habiendo sido designada para ello en el ejercicio de funciones públicas' (STS 8.5.92). Y así han de incluirse 'los llamados funcionarios de hecho que desempeñan una función pública, aunque no reúnan todas las calificaciones o legitimaciones requeridas' (STS 30.9.92), así como internos, sustitutos, pues 'los funcionarios de empleo', en contraposición de los funcionarios de carrera, tienen similar cuadro de derechos y obligaciones que los recogidos en el propio Estatuto de los funcionarios de propiedad (SSTS 20.5.93 y 9.10.91), la conducta imputada por el recurrente haber informado favorablemente la concesión de licencia para la ejecución del precepto de urbanización y parcelación que infringía las normas urbanísticas vigentes a sabiendas de su injusticia no pude entenderse cometida".

Así también las consideraciones de la STS 537/2002, 5-4: "La sentencia 2361/2001, de 4 de diciembre dice que esta Sala ha establecido en torno al 
Ya en este sentido cabe citar resoluciones más antiguas, como por ejemplo la STS 218/1995, 10-2, que consideraba funcionario público a una persona contratada para recaudar impuestos, con base en un contrato administrativo de la Ley de Contratos con la Administración pública; o la SAP Guadalajara 55/1996, 24-6, que catalogaba como funcionario público a efectos penales (si bien en el caso concreto se absolvió al acusado del delito de denegación de auxilio que se le imputaba) al conductor de un servicio de ambulancias, puesto que tal servicio

concepto penal de funcionario público que se considera como tal a todo el que por disposición inmediata de la ley o por elección o por nombramiento de autoridad competente participe del ejercicio de funciones públicas (artículo 119 CP y artículo 24.2 del vigente Código Penal). Doctrina y jurisprudencia coinciden en resaltar que los conceptos que se contienen en el artículo 119 del Código Penal son más amplios que los que se utilizan en otras ramas del ordenamiento jurídico y más concretamente en el ámbito del derecho administrativo.

Mientras que para el Derecho administrativo los funcionarios son personas incorporadas a la Administración pública por una relación de servicios profesionales y retribuidos, regulada por el derecho administrativo, por el contrario, el concepto penal de funcionario público no exige las notas de incorporación ni permanencia, sino la mera participación en la función pública. La definición legal de funcionario público recogida en el artículo 119 -artículo 24.2 del vigente Código Penal- se compone de dos elementos o requisitos ya que no es suficiente con que participe en el ejercicio de funciones públicas sino que se requiere, además, que se haya incorporado a dicho ejercicio por disposición inmediata de la ley o por elección o por nombramiento de autoridad competente (STS de 10 de octubre de 1997), precisando que en el ámbito del derecho penal lo que importa es proteger penalmente el ejercicio de la función pública en orden a sus propios fines, garantizando a un tiempo los intereses de la administración (y su prestigio) y los de los administrados. Y en torno a la función pública y al origen del nombramiento gira la definición penal de funcionario: lo es el que participa del ejercicio de una función pública y por cualquiera de las tres vías de designación que recoge el precepto, de las que nos interesa en este caso el «nombramiento de autoridad competente». Nada importan en este campo ni los requisitos de selección para el ingreso, ni la categoría por modesta que fuere, ni el sistema de retribución, ni el estatuto legal y reglamentario, ni el sistema de previsión, ni aun la estabilidad o temporalidad (STS de 11 de octubre de 1993 y las que en ella se citan)".

En la misma línea, vid. asimismo STS 83/2017, 14-2; STS 149/2015, 11-3; STS 421/2014, 16-5; STS 166/2014, 28-2; STS 1590/2003, $22-4$. 
se prestaba en virtud de un contrato entre la Administración (el INSALUD) y una empresa privada, que recibía el encargo de prestar este servicio sanitario ${ }^{40}$. Esta consideración, no obstante, ha venido modulada por el grado de responsabilidad que tiene la persona en el ámbito de la empresa gestora de un servicio público; así, la STS 1122/2007, 10-12, afirmaba que no cabía atribuir la condición de funcionario público a un mecánico de una empresa responsable de la inspección técnica de vehículos, puesto que no se constató que él ostentara la dirección de la empresa.

Así, y como dice la STS 149/2015, 11-3: "Se impone en este punto, más que en otros, un ponderado "levantamiento del velo": estar a la realidad esencial, y no al ropaje formal. La huida del derecho administrativo, fenómeno bien conocido y teorizado por la doctrina especializada, no puede ir acompañada de una "huida del Derecho Penal", sustrayendo de la tutela penal reforzada bienes jurídicos esenciales, por el expediente de dotar de apariencia o morfología privada a lo que son funciones propias de un organismo público desarrolladas por personas que han accedido a su cargo en virtud de la designación realizada por una autoridad pública, aunque la formalidad jurídica externa (contrato laboral de Alta Dirección, elección por el órgano de gobierno de una mercantil) encubra o se superponga de alguna manera a esa realidad material" ${ }^{41}$.

En suma, al igual que en los casos de las sociedades mercantiles públicas y de las corporaciones, cabe propugnar, a efectos de la aplicación de la pena de inhabilitación, que desempeñan un cargo público quienes están vinculados con la Administración pública en la ejecución de un contrato administrativo de los regulados en la Ley de Contratos del Sector Público, siempre

40 Vid. más ejemplos en MARTíN LORENZO, M., "Concepto penal de funcionario y externalización de funciones públicas", en MAQUEDA ABREU, M. / MARTÍN LORENZO, M. / VENTURA PÜSCHEL, A. (Coord.), Derecho Penal para un estado social y democrático de derecho. Estudios penales en homenaje al profesor Emilio Octavio de Toledo y Ubieto, Universidad Complutense de Madrid, Madrid, 2016, pp. 217-218 y 226-227.

41 Vid. así también la STS 421/2014, 16-5; y la STS 166/2014, 28-2. 
que participen en la efectiva realización de funciones públicas, lo cual será constatable teniendo en cuenta la naturaleza del objeto de tales contratos. Ello permitiría, por lo tanto, centrar la responsabilidad y la consideración como cargo público en las personas que reciben expresamente la asignación formal de la concreta función, y que son responsables ante la Administración de su correcto cumplimiento, dejando al margen aquellas otras personas que simplemente desarrollan tareas puramente ejecutivas dentro de la entidad que, en virtud del contrato administrativo, se dedica a la prestación de un determinado servicio.

Como conclusión, puede afirmarse que la defensa de un concepto predominantemente material de cargo público, centrado en el ejercicio de funciones o actividades propias de la Administración, elimina la posible rigidez de la pena de inhabilitación y permite su aplicación a todos los casos en que se verifiquen sus fundamentos, independientemente de la evolución de las formalidades jurídicas que revista el ejercicio de las funciones públicas, y del posible uso fraudulento de determinadas modalidades de vinculación con la Administración. Así, será indiferente si un sujeto está en el seno de la Administración pública en virtud de una relación funcionarial o laboral, o si su actividad se desarrolla en el marco de un contrato administrativo cuando sería procedente un contrato de trabajo; lo relevante es el auténtico ejercicio de actividades propias de la Administración, que derivan realmente del conjunto de fines que persigue el Estado. De este modo, ante la inevitable situación actual y la previsible acentuación de los fenómenos de gestión indirecta y liberalización, resultaría conveniente repensar y reformular el contenido esencial de esta pena con el objeto de adaptarla a las nuevas realidades de definición y prestación de servicios públicos.

Debe tenerse presente que el fundamento y esencia de esta sanción se centra en apartar de una función de interés general, esto es, la participación en los servicios y tareas públicas, a quienes han realizado determinados comportamientos delictivos que, o guardan relación con el puesto desempeñado, o son de 
tal gravedad que hacen a la persona inapropiada para participar en el desarrollo de tareas públicas ${ }^{42}$. Tradicionalmente, quienes desempeñaban estas funciones se hallaban vinculados con la Administración de forma directa, conexión que, como acabamos de ver, puede pasar desde una integración completa del sujeto como funcionario público hasta un contrato laboral. Si progresivamente desaparece o se diluye esa relación con la Administración, no por ello cabe negar que se esté participando de forma efectiva en la gestión y prestación de servicios públicos. Por lo tanto, cabe abogar por una interpretación predominantemente material de esta pena, para que pueda afectar a todo aquel que ejerce funciones públicas o presta servicios públicos, sin olvidar que ha de existir también algún tipo de vinculación formal con la Administración, pero sin exigir unas modalidades estrictas en esta conexión formal.

De hecho, como ya se ha anticipado, esta interpretación material propugnada esencialmente para el concepto de cargo público, ya está presente en uno de los dos elementos de la propia definición legal del término funcionario público a efectos penales. El artículo 24 del Código Penal considera funcionario público a "todo el que por disposición inmediata de la ley o por elección o por nombramiento de autoridad competente participe en el ejercicio de funciones públicas". Se comprueba, por lo tanto, que la esencia del concepto de funcionario público se halla en la participación en funciones públicas, si bien se exige asimismo una determinada vinculación formal con la Administración, que el Código Penal configura de forma amplia, puesto que admite que la condición de funcionario derive del nombramiento de la autoridad competente, de una elección o de una disposición legal ${ }^{43}$.

42 Vid. destacadamente una exposición de los fines de estas penas privativas de derechos, GUTIÉRREZ CASTAÑEDA, A., Las penas privativas de derechos politicos y profesionales, Tirant lo Blanch, Valencia, 2012, pp. 279 ss. y 455 ss.

43 Vid. sobre el concepto de funcionario público en el ámbito penal (tanto en el ámbito doctrinal como en el jurisprudencial), entre otros, ALONSO PÉREZ, F., Delitos cometidos por los funcionarios públicos en el nuevo Códi- 
Para tratar de aportar contornos adecuados a este concepto de cargo público, es interesante retener el elemento de "participación en funciones públicas", propio del concepto de funcionario público del artículo 24 del Código Penal, puesto que en este trabajo se propone centrar la esencia del concepto de cargo público (y realmente, de la propia pena de inhabilitación) en esta circunstancia, y quitar relevancia a la clase de vinculación formal del sujeto con la Administración, que como se ha ido comprobando es variada y cambiante a lo largo del tiempo (lo cual no implica, en cualquier caso, prescindir de algún tipo de vinculación formal); lo que interesa, realmente, es apartar al sujeto del ejercicio de funciones públicas, independientemente de la cobertura formal bajo la cual las ejerza.

go penal, Dykinson, Madrid, 2000, pp. 34-37; GONZÁLEZ CUSSAC, J.L., El delito de prevaricación de autoridades y funcionarios públicos, Tirant lo Blanch, Valencia, 1997, pp. 99 ss.; JAVATO MARTÍN, A.M., "El concepto de funcionario y autoridad a efectos penales", en Revista Jurídica de Castilla y León, 2011, nº 23, pp. 152 ss.; MARTÍN LORENZO, M., "Concepto penal de funcionario y externalización de funciones públicas”, cit., pp. 213 ss.; MIR PUIG, S. / GÓMEZ MARTÍN, V., "Artículo 24”, en CORCOY BIDASOLO, M. / MIR PUIG, S. (Dir.), Comentarios al Código Penal, Tirant lo Blanch, Valencia, 2015, pp.156-158; OLAIZOLA NOGALES, I., "Concepto de funcionario público a efectos penales", en ASÚA BATARRITA, A. (Ed.), Delitos contra la Administración pública, Instituto Vasco de Administración Pública, Bilbao, 1997, pp. 77 ss.; la misma autora, El delito de cohecho, Tirant lo Blanch, Valencia, 1999, pp. 125 ss., y especialmente pp. 168-169; PUENTE ABA, L.M., La pena de inhabilitación absoluta, cit., pp. 63 ss.; QUERALT, J.J, "El concepto de funcionario público", en Cuadernos de politica criminal, 1985, $\mathrm{n}^{\circ}$ 27, pp. 477-508; QUINTERO OLIVARES, G., "Artículo 24", en QUINTERO OLIVARES, G. (Dir.), Comentarios al Código Penal español, Tomo I, Thomson Reuters Aranzadi, Cizur Menor, 2016, pp. 330-335; RAMON RIBAS, E., "La derogación jurisprudencial del artículo 24.2 CP (concepto de funcionario público)" en Estudios Penales y Criminológicos, 2014, vol. XXXIV, pp. 174 ss.; ROCA AGAPITO, L., "Concepto de autoridad y de funcionario público a efectos penales", en Revista Aranzadi de Derecho y Proceso Penal, 2013, no 31, pp. 4 ss.; VALEIJE ÁLVAREZ, I., "Reflexiones sobre los conceptos penales de funcionario público, función pública y personas que desempeñan una función pública", en Cuadernos de politica criminal, 1997, n 62, pp. 445 ss.; VÁZQUEZ PORTOMEÑE SEIJAS, F., Los delitos contra la Administración Pública. Teoría general, Universidade de Santiago de Compostela, 2003, pp. 348 ss. 
Evidentemente, es innegable que de este modo se presenta la dificultad de definir qué se entiende por "funciones públicas", sobre todo porque, como ya se ha ido indicando, muchas actividades tradicionalmente desempeñadas por la Administración pasan a ser gestionadas ahora por operadores privados, lo cual hace surgir la duda sobre si tales actividades no pueden ser ya consideradas como funciones públicas, o si realmente siguen siendo funciones de carácter público pero gestionadas por particulares ${ }^{44}$. Es cierto que el concepto de interés general, bien común o actividad de interés público es de naturaleza cambiante, pero ello no lo invalida para constituir la esencia material de la noción de función pública. De hecho, es normal y admisible que un concepto se modifique a lo largo del tiempo, y resulta imposible una respuesta universal e inmutable sobre los fines de interés general que ha de perseguir el Estado, ya que depende de cada momento histórico, de la concreta configuración del Estado, y de la ideología que subyace a la estructura estatal y a la comunidad social. Únicamente en cada etapa cabrá acotar tal concepto desde la perspectiva de la configuración del Estado; así, desde el punto de vista del Estado democrático de Derecho existe un buen número de actividades que no hay duda en calificar de interés público, como la sanidad, la educación, la justicia, etc., y en todo caso siempre se puede recurrir, al margen de interpretaciones teóricas coyunturales, a los objetivos marcados en

44 Vid. en relación con estas cuestiones JAVATO MARTÍN, A.M., "El concepto de funcionario y autoridad a efectos penales", cit., pp. 157 ss.; ROCA AGAPITO, L., "Concepto de autoridad y de funcionario público a efectos penales", cit., pp. 8 ss.: en el análisis de la definición del concepto de funcionario público a efectos penales, se ponen ya de relieve las dificultades derivadas de la difuminación entre actividades públicas y privadas, como consecuencia de las diversas modalidades de cesión a manos privadas de la gestión de determinadas funciones previamente asumidas de forma directa por la Administración pública. Vid. también MARTíN LORENZO, M., "Concepto penal de funcionario y externalización de funciones públicas", cit., pp. 226-227, haciendo hincapié en la necesidad de no supeditar la tutela penal a la pervivencia de las tradicionales formas de organización de la Administración pública. 
la propia Constitución ${ }^{45}$. Habría que intentar fundamentar este concepto en todas aquellas actividades o prestaciones necesarias de interés general, es decir, indispensables para la satisfacción de las necesidades básicas de los ciudadanos.

En suma, cabe concluir que la esencia del concepto de función pública ha de estar en la realización de actividades destinadas a satisfacer los intereses generales, y que por este motivo corresponde al Estado su ejecución; por ello, habrá de considerarse función pública aquella actividad que presenta estos caracteres aunque se halle desvinculada parcialmente de los órganos públicos y del Derecho público, pero que realmente corresponde al Estado ${ }^{46}$. Este concepto podría pivotar en torno a dos ejes fun-

45 Vid. SÁNCHEZ MORÓN, M., Derecho administrativo. Parte general, cit., pp. 74 ss., poniendo de relieve que los fines e intereses que ha de perseguir la Administración pública han de ser determinados por los poderes constitucionales. Vid. también SANTAOLALLA LÓPEZ, F., Derecho constitucional, Dykinson, Madrid, 2010, cit., pp. 58-60. Puede verse, poniendo de relieve el devenir histórico del concepto de "servicio público", VAQUER CABALLERÍA, M., "De nuevo sobre la doctrina europea de los servicios de interés general: los problemas para definir la familia de los 'servicios sociales' y su aplicación en materia de vivienda”, en Revista General de Derecho administrativo, $\mathrm{n}^{\circ} 25,2010$, pp. 1 ss.

Cfr. en la doctrina penal OLAIZOLA NOGALES, I., El delito, cit., pp. 133-134.

46 Como refuerzo de esta interpretación fundamentalmente material del concepto de función pública, cabe mencionar aquí un ejemplo de equiparación que efectúa el propio Código Penal entre particulares y funcionarios públicos, concretamente en relación con el delito de malversación de caudales públicos. Si bien este delito en principio sólo puede ser cometido por autoridades o funcionarios públicos, el artículo 435 del Código penal establece que se equipararán a estos sujetos, a efectos de la comisión de este delito, por ejemplo, los particulares legalmente designados como depositarios de caudales o efectos públicos, o los que se hallen encargados por cualquier concepto de fondos, rentas o efectos de las Administraciones públicas. Así, la propia ley sitúa en la misma posición que las autoridades o funcionarios públicos a ciudadanos particulares, y la fundamentación de esta equiparación se ha situado precisamente en que, en las situaciones citadas (ser depositario o encargado de diferentes tipos de bienes públicos), el particular realmente participa de hecho en una función pública, en la misma posición que una autoridad o funcionario; si en el ejercicio de tales facultades realiza un ataque contra la función pública, se considera que ha de ser castigado como si fuera un auténtico funcionario que participa en estas mismas tareas: 
damentales: por un lado, la satisfacción de un interés general, el cumplimiento de un fin propio del Estado; por otro lado, la regulación de tal actividad por normas de Derecho público. En cualquier caso, siempre debería aceptarse la imposibilidad de ofrecer una definición rígida y absoluta de interés general o fin público, y además, habría que admitir que las modalidades formales de vinculación a la Administración para el ejercicio de una función pública pueden ser extremadamente variables. Así, cabría considerar en este sentido que ejercen una función pública personas que no son formalmente empleados públicos de acuerdo con el Estatuto básico del empleado público, ni tienen un cometido que se acomode a un concepto tradicional de cargo público, pero que materialmente participan en el ejercicio de actividades prestacionales propias de la Administración. Así, se incluirían en este concepto amplio y material de cargo público las personas que realizan esta clase de funciones al amparo de un contrato administrativo, en el seno de una sociedad mercantil pública, o ejerciendo determinadas funciones dentro de una corporación sectorial de base privada.

Realmente sería preferible que el texto legal prescindiera de la referencia exacta a empleos o cargos públicos, y denominase esta sanción como una "inhabilitación para funciones públicas" ${ }^{" 47}$, puesto que sería más adecuado interpretar esta última expresión en el sentido amplio, de fundamentación predominantemente material (si bien exigiendo al menos algún tipo de encargo formal por parte de las Administraciones públicas), que se está exponiendo en este trabajo. Bien es cierto que esto otorga unos contornos más amplios a esta sanción, pero una deseable limitación de sus efectos podría lograrse, de entrada, exigiendo una conexión entre la infracción cometida y la función pública

vid. al respecto CASTRO MORENO, A., La malversación de caudales en el Código penal de 1995, Tirant lo Blanch, Valencia, 2001, p. 88; ROCA AGAPITO, L., El delito de malversación de caudales públicos, Bosch, Barcelona, 1999, p. 306.

47 Al estilo de otros ordenamientos jurídicos de nuestro entorno; vid. al respecto PUENTE ABA, L.M., La pena de inhabilitación absoluta, cit., pp. 10 ss. 
objeto de privación, tanto si la pena es prevista como principal o como accesoria; asimismo, en determinados casos podría limitarse la prohibición penal a concretos aspectos de la función pública, que se hallen vinculados con el concreto delito cometido (v.gr. el ejercicio de funciones públicas relacionadas con el manejo de dinero, o con el mantenimiento de la seguridad pública, o con la enseñanza, etc.). Precisamente estas dos propuestas constituyen cuestiones problemáticas que se presentan actualmente en relación con la aplicación de esta pena de inhabilitación, tal y como se analizará en los epígrafes siguientes.

\section{La especificación del empleo o cargo público afectados por la condena}

Si bien la pena de inhabilitación absoluta no plantea especiales problemas de aplicación, puesto que afecta a todos los empleos o cargos públicos del penado, la pena de inhabilitación especial afecta a un empleo o cargo concreto, lo cual exige su concreción en la sentencia; así lo dispone el artículo 42 del Código Penal, exigiendo expresamente que los empleos o cargos afectados se especifiquen en la propia sentencia. Por obvio que parezca, lo cierto es que resulta frecuente encontrar sentencias cuyo fallo condena escuetamente a la pena de inhabilitación especial para empleo o cargo público, sin especificación alguna, y no solo en fallos condenatorios de sentencias de Audiencias Provinciales, sino incluso en resoluciones del Tribunal Supremo. Así, como muestra de estas últimas, pueden citarse como ejemplo, entre otras, la STS 213/2018, 7-5 (caso La Muela), la STS 625/2015, 22-12 (caso Malaya) o la STS 990/2013, 30-12 (caso Inspección Tributaria de Cataluña); todas ellas son sentencias condenatorias que imponen la pena de inhabilitación especial para empleo o cargo público sin mayor precisión, esto es, sin indicar a qué cargo/s afecta la sanción.

Si bien es cierto que en muchos casos esta importante omisión en el fallo condenatorio se trata de solventar a través de 
un auto de aclaración de sentencia ${ }^{48}$, es habitual que tal omisión sea corregida por un tribunal superior que resuelve un recurso contra la sentencia. Así, nos encontramos con sentencias del Tribunal Supremo que específicamente reforman la resolución de instancia precisando la necesidad de concretar el cargo o empleo afectados por la pena de inhabilitación especial. En primer lugar, cabe citar como ejemplo la STS 704/2011, 1-7, corrigiendo la sentencia de instancia, que había impuesto una pena de inhabilitación especial para empleo o cargo público sin más especificación. Uno de los motivos del recurso de casación, precisamente, se centraba en esta cuestión, y el Alto Tribunal concreta la pena fijando la inhabilitación "para el cargo de Alcalde, Teniente de Alcalde, Concejal o cualquier otro de naturaleza electiva y ámbito local que implique una participación en el Gobierno Municipal" (el condenado tenía el cargo de Alcalde).

La expresión del cargo o empleo público debería ser concreta, fijándose claramente el/los cargo/s o empleo/s individualizado/s que va/n a ser objeto de privación definitiva por parte del Tribunal. Esta precisión es necesaria a la vista de fallos condenatorios como el de la STS 214/2018, 7-5 (caso Gürtel - Fitur), en la que se confirman las condenas de instancia

48 Así ocurrió, por ejemplo, en relación con el caso enjuiciado en la STS 88/2018, 21-2: la SAP Valencia 32/2017, 23-1, impuso sin mayor precisión la pena de inhabilitación especial para empleo o cargo público, y el 10-22017 el mismo Tribunal dictó Auto de aclaración de sentencia (aclaración instada por el condenado) en el que precisó que tal sanción implicaba "la privación del cargo efectivo de Alcalde electo, que desempeñaba durante la comisión de los hechos y que sigue desempeñando en la actualidad, junto con el tratamiento anejo al cargo, uso de medallas o distintivos cualesquiera; honores que le sean anejos, cobro de percepciones, dietas, recompensas o indemnizaciones, y cualesquiera otros emolumentos con cargo a fondos públicos que se encuentren previstos en la legislación de régimen local, debiendo extenderse a la incapacidad para obtener el mismo cargo, u otros análogos de prestación de servicios en régimen funcionarial en cualquier administración pública, nacional, autonómica o local". El TS suprimió, en relación con la incapacidad para adquirir otros cargos o empleos análogos, la referencia a los empleos o cargos para la prestación de servicios en régimen funcionarial, restringiéndolos a los de procedencia electiva. 
a penas de inhabilitación especial (entre otras), que afectan tanto a autoridades como a particulares. Aquí se imponen penas de inhabilitación especial para el desempeño de empleos o cargos públicos relacionados con actividades propias de la contratación administrativa, tanto a particulares (empresarios) por el delito de asociación ilícita como a autoridades por el delito de prevaricación. Esta condena suscita distintas reflexiones en función de ambas categorías de sujetos afectados por la pena.

Por un lado, en relación con las autoridades, la sentencia debería indicar expresamente cuál es el concreto cargo público objeto de privación, sin realizar una referencia general a empleos o cargos relacionados con la contratación administrativa. Esta caracterización, a lo sumo, podría emplearse como criterio definidor de los empleos o cargos análogos a los que no podrá acceder el condenado durante el tiempo de la condena, pero no constituye el modo de precisar el primer efecto de la pena: la privación definitiva de un concreto empleo o cargo, que además servirá como referencia para determinar cuáles son los otros empleos o cargos análogos a los cuales será imposible acceder durante el tiempo que dure la condena.

Por otro lado, resulta mucho más difusa e inapropiada esta expresión en relación con los condenados que no poseen la condición de empleados públicos ni de cargos públicos: los particulares (empresarios) condenados, entre otros delitos, por el de asociación ilícita. Aquí, sin duda, subyace la dificultad derivada de la previsión de una pena de inhabilitación para empleo o cargo público para un delito que, por definición, no guarda conexión alguna con el hecho de ostentar uno de estos empleos o cargos. De este modo, si el condenado no posee ningún empleo o cargo público, no podrá ser objeto de ninguna privación y, por extensión, tampoco podría impedírsele acceder a otros empleos o cargos públicos; como indica el art. $42 \mathrm{CP}$, el segundo efecto de esta pena de inhabilitación es la incapacidad para acceder al mismo empleo o cargo objeto de privación, o a otros análogos a este último: por consiguiente, difícil resulta establecer una 
analogía con un empleo o cargo si el condenado no ostentaba ninguno de ellos.

En fin, y concluyendo con las puntualizaciones relativas a la precisión de las penas privativas de derechos en esta sentencia, llama la atención la expresión de la condena impuesta por el delito de malversación a determinadas autoridades, puesto que se indica expresamente que la pena es "inhabilitación absoluta para el desempeño de empleos o cargos públicos relacionados con actividades propias de la contratación administrativa". Atendiendo al art. $41 \mathrm{CP}$, es evidente que si la pena impuesta es realmente la de inhabilitación absoluta, afecta a todos los empleos y cargos públicos que posea el condenado, y determina la incapacidad general para acceder a cualquier otro empleo o cargo durante el tiempo de la condena, de tal modo que precisamente en esta pena no es necesario realizar ningún esfuerzo de concreción.

En conclusión, es imprescindible que el fallo condenatorio precise de forma clara y taxativa cuál es el concreto empleo o cargo público objeto de privación ${ }^{49}$. Solo a partir de ahí será posible determinar a qué otros cargos o empleos análogos está prohibido acceder durante el tiempo que dure la condena. Si bien, como más adelante se verá, tradicionalmente se han señalado las dificultades que pueden surgir para establecer tal analogía, lo cierto es que ya podemos encontrarnos con posibles interrogantes en el momento de fijar el concreto empleo o cargo del que se priva al penado; a esta cuestión se dedicará el epígrafe siguiente.

\section{Elección del empleo o cargo público específico afectados por la condena}

Una primera cuestión problemática que podemos encontrar a la hora de fijar el empleo o cargo afectados por la condena, es la relativa a la posibilidad de fragmentar las diversas com-

49 Vid. con respecto a la concreción de los empleos o cargos afectados, GILI PASCUAL, A., "La inhabilitación para empleo público en el Derecho penal actual”, en Cuadernos de política criminal, n 124, 2018, p. 165. 
petencias o facetas de un mismo empleo o cargo, de tal modo que el condenado lo conserve pero se le prohíba desempeñar determinadas funciones que le son propias. Podría parecer que la pregunta no tiene sentido, considerando que el Código Penal siempre se refiere a "empleo o cargo público", no a la realización de actividades propias de un empleo o cargo, mención que sí podría dar lugar a la prohibición de llevar a cabo determinadas tareas pero pudiendo continuar con la realización de otras $\mathrm{y}$, fundamentalmente, conservando la titularidad del empleo o cargo $^{50}$. No obstante, esta cuestión se ha planteado en la práctica judicial, y encontramos jurisprudencia del Tribunal Supremo que se manifiesta al respecto, poniendo de relieve la existencia de diversidad de interpretaciones en nuestros tribunales.

Así, cabe comenzar por el caso que resolvió el TS en su sentencia 887/2008, 10-2. El tribunal de instancia condenó a los dos acusados por un delito de revelación de secretos por funcionario público, aplicándoles la pena de inhabilitación especial que les privó de su condición de bomberos, como funcionarios municipales. Dado que el delito había sido cometido con ocasión de su intervención como miembros de un tribunal encargado de evaluar las pruebas selectivas para el acceso, vía concurso - oposición, a plazas de bombero funcionario del Ayuntamiento, los condenados alegaron, en su recurso de casación, que la inhabilitación debería haber recaído sobre su condición de cargos electos para un tribunal de oposiciones, no sobre su empleo público de bomberos. A esta pretensión se opuso el Tribunal Supremo, alegando que "la condición de miembro de un tribunal de oposiciones no encierra, si bien se mira, el ejercicio de un empleo, ni siquiera el de un cargo. Se trata de un cometido funcional sólo explicable por la condición del recurrente de funcionario-bombero del Ayuntamiento de Granada. Dicho con otras palabras, se es funcionario y se está en un tribunal de opo-

50 Clase de mención que sí aparece, por ejemplo, en el ámbito de las penas aplicables a personas jurídicas (art. 33.7 CP), donde sí se alude a la prohibición de realizar determinadas actividades en cuyo ejercicio se haya cometido el delito. 
siciones. La pena de inhabilitación especial (art. $42 \mathrm{CP}$ ) no tiene por fundamento la privación selectiva de concretas parcelas funcionales. Su significado como pena restrictiva de derechos mira de modo preferente al empleo o cargo público como tal, esto es, al título jurídico que habilita para el ejercicio de esas otras ocupaciones de carácter temporal. De ahí que a la hora de definir el contenido de la inhabilitación, ésta ha de conectarse con la función raíz, con la actividad que está en el origen del delito, no con los desempeños puramente ocasionales y que sólo se explican por razón de un empleo o cargo que preexiste y que es, en última instancia, el que ha de quedar afectado por la pena. De ahí la corrección del criterio de la Sala de instancia cuando razona que '...la condena sólo habrá de recaer sobre la cualidad funcionarial que los dos detentaban en cuyo ámbito cometieron el delito imputado, esto es, la de bomberos del Ayuntamiento de Granada en atención a la cual, por la representación sindical que ostentaban como tales funcionarios, fueron designados miembros del tribunal de oposiciones en el ejercicio de cuya función cometieron la infracción penal"'.

En esta línea continúa la jurisprudencia reciente del Tribunal Supremo; así, cabe examinar la STS 88/2018, 21-2, que afirma: "respecto a la concreción del alcance de la pena de inhabilitación especial para empleo o cargo público, la jurisprudencia de esta Sala tiene proclamado que la inhabilitación especial no tiene por fundamento la privación selectiva de concretas parcelas funcionariales, sino que su significado -como pena restrictiva de derechos-mira de modo preferente al empleo o cargo público como tal, esto es, al título jurídico que habilita, tanto para el ejercicio de las ocupaciones laborales básicas, como a cualquiera otras de carácter temporal que puedan estarle vinculadas; esto es, que a la hora de definir el contenido de la inhabilitación, ésta ha de conectarse con la función raíz o la actividad que está en el origen del delito, no con los desempeños puramente ocasionales (SSTS 695/2012 de 19 de septiembre; 887/2008, de 10 de diciembre)"51.

51 Vid. asimismo la STS 314/2017, 3-5 y la STS 426/2016, 19-5.

Vid. también, pronunciándose en contra de esta forma de fragmentar los 
Sin duda la acción de limitar de la forma indicada el alcance de la pena de inhabilitación pretende reducir el carácter especialmente gravoso de la sanción en determinados casos concretos, puesto que indudablemente estamos ante una pena que puede tener muy diverso contenido aflictivo en función del sujeto a quien se impone ${ }^{52}$. No obstante, atendiendo a la definición legal de la pena de inhabilitación, no resulta admisible tal fragmentación, y la consecuencia de la aplicación de esta sanción es la pérdida definitiva de la titularidad del empleo o cargo público. Tal posibilidad solo sería viable, como se ha indicado en el epígrafe II, en el caso de que esta pena viniera definida como una inhabilitación para funciones públicas, de tal modo que el juzgador tuviera la opción de seleccionar concretas funciones o actividades al aplicar esta pena al condenado.

Al margen de esta cuestión relativa a la división o fragmentación de las distintas actividades o facetas de un mismo empleo o cargo público, se plantea también la problemática de cómo aplicar la pena de inhabilitación especial para empleo o cargo público cuando el sujeto posee dos empleos o cargos. Las situaciones que podrían plantearse son sin duda muy heterogéneas; sin ánimo de exhaustividad, cabe plantear aquí las siguientes posibilidades:

1. Persona que tiene simultáneamente dos empleos públicos, o que desempeña a la vez un empleo y un cargo público.

empleos y cargos públicos, CARDENAL MONTRAVETA, S., "Artículo 42", en CORCOY BIDASOLO, M. / MIR PUIG, S. (Dir.), Comentarios al Código Penal, cit., p. 214; GUTIÉRREZ CASTAÑEDA, A., en ROCA DE AGAPITO, L. (Dir.), Las consecuencias jurídicas del delito, Tirant lo Blanch, Valencia, 2017, p. 53; MAPELLI CAFFARENA, B., Las consecuencias jurídicas del delito, Civitas Thomson Reuters, Madrid, 2011, p. 264; RÍOS, J. / PASCUAL, E. / ETXEBARRIA, X., Manual sobre las consecuencias jurídicas del delito: su determinación y aplicación, Universidad Pontificia de Comillas, Madrid, 2016, p. 67.

52 Vid. GILI PASCUAL, A., "La inhabilitación para empleo público en el Derecho penal actual", cit., pp. 149-150; MAPELLI CAFFARENA, B., "La pena de inhabilitación absoluta, ¿es necesaria?”, en Cuadernos de política criminal, $\mathrm{n}^{\mathrm{0}} 108,2012$, pp. 11 ss. 
En el primer supuesto, cabe pensar en determinados funcionarios públicos como médicos, jueces o fiscales que simultáneamente imparten docencia universitaria, y a cualquier otro supuesto que se enmarque en el régimen de la Ley 53/1984, 26-12, de incompatibilidades del personal al servicio de las Administraciones Públicas ${ }^{53}$; en el segundo caso estarían, por ejemplo, quienes desempeñan cargos electivos en régimen de dedicación no exclusiva (art. 5 de la citada Ley 53/1984) ${ }^{54}$.

2. Empleado público que está desempeñando un cargo público, por designación o por elección, y que por ese motivo está en situación de servicios especiales (art. 87 del Estatuto Básico del Empleado Público) ${ }^{55}$; a este supuesto podría asimilarse el nombramiento de un funcionario de una Corporación local, por razones de urgencia y necesidad, para desarrollar las funciones de puestos reservados a funcionarios de Administración local con habilitación de carácter nacional en caso de ausencia de su titular (destacadamente, Secretarios e Interventores accidentales).

3. Persona titular de un determinado empleo o cargo público en el momento de cometer el delito, pero que posee otro empleo o cargo diferente al tiempo del enjuiciamiento.

La problemática común a situaciones como las mostradas en los puntos 1 y 2 se centra en determinar a qué empleo o cargo afecta la pena de inhabilitación especial. Surge la dificultad de establecer criterios de selección del concreto cargo o empleo objeto de privación, sobre todo teniendo en cuenta que ni el Có-

53 Vid. PALOMAR OLMEDA, A. / VÁZQUEZ GARRANZO, J., Practicum Función pública 2017, cit., pp. 367 ss.; PARADA, R. / FUENTETAJA, J., Derecho de la función pública, cit., 2019, p. 523; SÁNCHEZ MORÓN, M., Derecho de la función pública, Tecnos, Madrid, 2018, pp. 331 ss.

54 Vid. PALOMAR OLMEDA, A. / VÁZQUEZ GARRANZO, J., ibídem; PARADA, R. / FUENTETAJA, J., ibídem; QUESADA LUMBRERAS, J.E., op. cit., pp. 740-741; SÁNCHEZ MORÓN, M., ibídem.

55 Vid. PALOMAR OLMEDA, A. / VÁZQUEZ GARRANZO, J., Practicum Función pública 2017, cit., pp. 225 ss.; PARADA, R. / FUENTETAJA, J., Derecho de la función pública, cit., pp. 379 ss. 
digo Penal ni la jurisprudencia exigen la relación entre el delito cometido y el empleo y cargo como fundamento de aplicación de la inhabilitación especial como pena principal. Efectivamente, según afirma de forma unánime la jurisprudencia, el empleo o cargo público afectado por la inhabilitación especial solo debe tener relación con el delito cometido cuando esta pena se impone como accesoria, pero no cuando está prevista como pena principal: así lo afirman, entre otras, la STS 259/2015, 30-4, la STS 426/2016, 19-5, y la STS 436/2016, 23-5. Efectivamente, el art. 56 CP exige la vinculación entre el delito cometido y el derecho afectado por la inhabilitación (en este caso, el empleo o cargo público) cuando esta pena se aplica como accesoria, requiriendo además que se manifieste expresamente en la sentencia esta vinculación. Tal conexión no se estipula ni en la definición genérica de esta pena en el art. $42 \mathrm{CP}$, ni en los concretos preceptos del Libro II del Código Penal que prevén esta sanción como pena principal. Por ello, ante supuestos como los enumerados anteriormente, e imponiéndose la inhabilitación como pena principal, podemos encontrar diversos criterios manejados por los Tribunales, que atienden a las peculiaridades de cada caso concreto.

Como primer ejemplo, cabe referirse a la STS 314/2017, 3-5. En este caso, se trataba de un funcionario del Cuerpo Auxiliar de la Administración de la Comunidad Autónoma, que había sido condenado en instancia por un delito de malversación cometido en el desempeño de sus cargos de Director General en el Gobierno autonómico y de Presidente del Consejo de Dirección de un Consorcio autonómico. El Tribunal de instancia, en un Auto de aclaración de sentencia, dictaminó que la pena de inhabilitación especial impuesta al condenado abarcaba todo empleo o cargo públicos, incluyendo no solo los concretos cargos que ostentaba al cometer el delito, sino también su condición de funcionario de carrera. Es interesante tener en cuenta los argumentos expuestos por el Tribunal Supremo en relación con la pena de inhabilitación especial, criticando la interpretación extensiva efectuada por el Tribunal de instancia (si bien, finalmente, no 
se estimó el recurso del condenado puesto que, además de la pena de inhabilitación especial, también se le había impuesto la de inhabilitación absoluta): "Las funciones en cuyo ejercicio se perpetraron los comportamientos delictivos, no fueron las propias de su condición de funcionario del cuerpo auxiliar, dado que el recurrente no estaba en activo en dicho cuerpo y perpetró el delito con ocasión del puesto de libre designación para el que había sido elegido, de Director General de Juventud, de la Consejería de Deportes y Juventud del Gobierno Balear. De hecho, la sentencia no sólo no establece ninguna vinculación entre los delitos cometidos y su puesto de funcionario del cuerpo auxiliar de la Comunidad Autónoma de las Islas Baleares, sino que ignora y desconoce por completo tal condición. Por último, la concreción que en su aclaración hace finalmente el Tribunal, a que la inhabilitación lo es para todo empleo o cargo público, bien sea de carrera o electo, para cualquier administración estatal, autonómica, insular o local, y sin ninguna discriminación de su vinculación con los hechos, parece situar la pena de inhabilitación especial en el espacio propio de la inhabilitación absoluta, con la dimensión omnicomprensiva que eso comporta y que la jurisprudencia de esta Sala rechaza (STS 552/2006, de 16 de mayo)".

Asimismo, destaca la STS 597/2014, 30-7. En este caso, la inhabilitación especial afectó a los cargos de Alcalde, Teniente de Alcalde y Concejal que poseían los condenados, y se estableció que no podrían acceder a cualesquiera otros cargos de naturaleza electiva y ámbito local que implicasen participación en el gobierno municipal, y asimismo otros análogos en el ámbito insular, autonómico o estatal. Aquí interesa señalar que uno de los acusados, el Teniente de Alcalde, solo perdió esta misma condición, en la cual había cometido el delito, pero continuó con su empleo público de Catedrático de Universidad.

Por el contrario, resuelve en forma diversa la STS $426 / 2016,19-5$, en relación con un funcionario público que había cometido el delito en el ejercicio del cargo de Subdelegado del Gobierno; había sido condenado en instancia a la pena de 
inhabilitación especial para empleo o cargo público, sin más precisión, y el Tribunal Supremo decidió privarle no solo de su cargo de Subdelegado del Gobierno, sino también de su condición de funcionario público. Razona la sentencia que "el cargo de Subdelegado del Gobierno es un cargo de libre designación para el que se requiere ser funcionario de carrera, de las Comunidades Autónomas o de las Entidades Locales, además de ostentar una titulación académica. Pretender que la inhabilitación especial afecta solamente al cargo de Subdelegado del Gobierno deja intacta la relación funcionarial o de empleo, restaría fuerza ejecutiva al sistema penal, pues el recurrente se valió de su posición de funcionario público para acceder a tal cargo, y el delito de tráfico de influencias quedaría en parte impune, mediante la simple artimaña de sustituir el cargo político por otro durante la tramitación del proceso penal, reduciendo a lo meramente simbólico la inhabilitación especial que como pena principal lleva consigo el referido delito. En el caso presente la petición del Ministerio Fiscal se concretó en la inhabilitación especial para el ejercicio de función pública y para todo cargo por lo que en aplicación de la doctrina jurisprudencial expuesta deberá concretarse la inhabilitación especial en todo cargo de carácter electivo o de designación en cualquier Administración Pública”.

Un supuesto de especial interés es el resuelto en la STS 259/2015, 30-4, ya que combina no solo la posible dualidad funcionario público - cargo público, sino que constituye exactamente el supuesto planteado en la posibilidad número 3 anteriormente indicada, esto es, persona que comete el delito ostentado un determinado cargo, pero que desempeña otro cargo diferente en el momento del enjuiciamiento. Este caso concreto se refiere a un sujeto que había cometido el delito en el desempeño de un cargo público en el Gobierno de la Comunidad Autónoma, pero en el momento de sentenciar el caso ya no desempeñaba este cargo, sino el de Diputado del Parlamento autonómico. A pesar de ello, el Tribunal de instancia decidió privarle de este cargo público en el Parlamento, resolución que mantuvo el Tribunal Supremo con base en los siguientes argumentos: "Es obvio que 
cuando el delito de prevaricación se comete en un cargo público de naturaleza política, como lo es el de miembro de Consejo de Gobierno de una Comunidad Autónoma, constituiría una burla al respeto que los ciudadanos deben al buen funcionamiento de los Poderes Públicos, que la pena de inhabilitación se limitase al cargo específico en el que se cometió la prevaricación, y permitiese al condenado seguir cometiendo esta clase de delitos en otro cargo análogo, fruto directo o indirecto de unas elecciones políticas, por el mero hecho de trasladarse de un cargo de representación política a otro similar, en el propio Gobierno Autonómico o de la Nación, en el Parlamento Autonómico, del Estado o de la Unión Europea, o en el ámbito municipal. [...] En consecuencia, la inhabilitación establecida como condena por el delito de prevaricación cometido por el miembro de un Consejo de Gobierno Autonómico, que en función de sus intereses políticos inmediatos prescindió de modo personal y directo de las exigencias esenciales del procedimiento de contratación administrativa, vulnerando todas las reglas establecidas para garantizar el control de los gastos públicos, debe extenderse a otros cargos públicos similares obtenidos por elección ciudadana, pues el representante que no ha sabido cumplir con las reglas de probidad y respeto de la legalidad en su gestión como Vice Consejero, difícilmente puede hacerse merecedor de la confianza en un cargo de representante parlamentario, en el que participa en las manifestaciones más importantes de la voluntad popular y del ejercicio del control político de la gestión del ejecutivo. [...] Lo que exige la norma legal, y también la jurisprudencia de esta Sala y del Tribunal Constitucional, es que la sentencia condenatoria especifique los empleos o cargos sobre los que recae la inhabilitación, en virtud del principio de interpretación restrictiva de la pena, para evitar una analogía generadora de indeterminación. $\mathrm{Y}$, en el caso actual, el Tribunal sentenciador ha especificado con concreción y claridad los cargos a los que se extiende la inhabilitación, incluyendo los de naturaleza política y excluyendo los que pudieran corresponder al condenado en su condición de mero funcionario. [...] Estimamos, conforme a la doctrina cita- 
da del Tribunal Constitucional, que condenar por prevaricación a un cargo electo, y mantenerle en su puesto como representante de los ciudadanos en un órgano legislativo mientras cumple la pena de inhabilitación especial impuesta, que es lo que solicita la defensa del condenado en este motivo de recurso, contradice la propia naturaleza de la pena principal y única establecida por el Legislador para el delito de prevaricación, vacía de contenido efectivo esta sanción penal, y reduce excesivamente la tutela del bien jurídico protegido por el delito de prevaricación, que garantiza el debido respeto, en el ámbito de la función pública, al principio de legalidad como fundamento básico de un Estado social y democrático de Derecho, y no excluye de su tutela el ámbito de los cargos de representación política en órganos parlamentarios".

En cambio, y en relación con la posible dualidad funcionario público - cargo público, la sentencia de instancia había determinado, en relación con esta concreta persona, que la pérdida del concreto cargo público (Diputado de Parlamento autonómico) "no implicará la pérdida de su condición de funcionario si la tuviera", cuestión que no fue rebatida por el Tribunal Supremo. Tal interpretación es la misma que se mantiene en relación con el otro sujeto condenado, pues el Tribunal determinó que la pena supondría la "pérdida de su condición de Jefe de cualquier órgano o unidad administrativa de libre elección o con funciones directivas si las tuviera en el momento de la condena, así como la imposibilidad de ser nombrado para ellas o para cualquier otro puesto representativo, ejecutivo o gestor por una autoridad pública, salvo aquellos puestos de RPT que se cubran por concurso, por dicho periodo, si bien, no implicará pérdida de su condición de funcionario".

También resulta de interés a estos efectos, planteando un supuesto ciertamente similar, el ATSJ Cataluña 23-11-2017, en relación con un delito de malversación cometido por un funcionario del Cuerpo de Gestión Procesal y Administrativa de la Administración de Justicia cuando no desempeñaba tal puesto, 
sino que era Letrado de la Administración de Justicia sustituto. El condenado alegaba que pertenecer al Cuerpo de Gestión no era requisito imprescindible para ser Letrado sustituto, pero el Tribunal consideró que sí era parcialmente determinante, pues constituía mérito preferente que le facilitaba acceder al puesto. De este modo, el Auto dispuso que la pena de inhabilitación especial (impuesta en sentencia del Tribunal del Jurado de 11 mayo 2017) incluía la privación definitiva del empleo de funcionario de Gestión Procesal y Administrativa de la Administración de Justicia que ostentaba el penado, así como la imposibilidad o incapacidad para recuperar dicho empleo o cargo, o para acceder al empleo de Letrado de la Administración de Justicia durante el tiempo de la condena.

En suma, tras la revisión de toda esta serie de casos parece que, si bien los Tribunales declaran como fórmula general que no es necesaria la vinculación entre el empleo o cargo y el delito cometido cuando la inhabilitación se impone como pena principal, a la hora de seleccionar el concreto empleo o cargo afectados por la condena se atiende a criterios como la vinculación del empleo o cargo con las actividades delictivas, o a la relevancia o carácter decisivo del empleo público para acceder al cargo en cuyo ejercicio se comete el delito. De este modo, puede afirmarse, y sin duda proponerse como criterio de interpretación, que aun cuando la inhabilitación especial se aplique como pena principal es adecuado atender a la relación entre el delito cometido y el empleo o cargo que serán objeto de privación ${ }^{56}$. Ello

56 A favor de vinculación con delito cometido o abuso de función pública, GILI PASCUAL, A., "La inhabilitación para empleo público en el Derecho penal actual”, cit., pp. 166-167; LÓPEZ BARJA DE QUIROGA, J., Tratado de Derecho Penal. Parte general, Civitas Thomson Reuters, Cizur Menor, 2010, p. 1253; MANZANARES SAMANIEGO, J.L., Comentarios al Código Penal español, Wolters Kluwer, Las Rozas, 2016, p. 223. En esta línea, manifiestan ORTS BERENGUER, E. / GONZÁLEZ CUSSAC, J.L., Compendio de Derecho Penal. Parte general, Tirant lo Blanch, Valencia, 2017 , p. 472, que la privación de un cargo público como consecuencia de la imposición de la pena de inhabilitación no tendría por qué conllevar la pérdida de la condición de funcionario público. Por su parte, CARDENAL 
resulta especialmente adecuado desde una perspectiva de prevención especial, puesto que se aparta al condenado del ámbito y función que ha empleado para cometer el delito; asimismo, teniendo en cuenta el potencial aflictivo de esta pena, se cumple un objetivo de prevención general pero modulado en función de la naturaleza y gravedad del delito ${ }^{57}$.

\section{La privación definitiva del empleo o cargo público}

Si bien los artículos 41 y 42 del Código Penal son claros al estipular que las penas de inhabilitación absoluta y especial producen la privación definitiva de los honores, empleos o cargos públicos afectados, no siempre se ha entendido claramente el alcance de este efecto de la pena.

El uso de tal término implica que el sujeto pierde el empleo, o deja de ostentar el cargo, o se le retiran los honores; tal privación no es una mera suspensión, de modo que no se recuperan los empleos, cargos u honores una vez cumplida la pena ${ }^{58}$.

MONTRAVETA, S., “Artículo 42”, cit., p. 214, precisa que, en principio, el empleo o cargo público que se pierde es aquel en cuyo ejercicio se cometió el delito. Se manifiestan también a favor de esta vinculación directa entre el delito y el empleo o cargo, GIL GIL, A. / LACRUZ LÓPEZ, J.M. / MELENDO PARDOS, M. / NÚÑEZ FERNÁNDEZ, J., Consecuencias jurídicas del delito. Regulación y datos de la respuesta a la infracción penal en España, Dykinson, Madrid, 2018, p. 153

57 Vid. sobre el cumplimiento de estos fines de la pena en relación con las penas privativas de derechos, PUENTE ABA, L.M., La pena de inhabilitación absoluta, cit., pp. 3 ss.

58 BOLDOVA PASAMAR, M.A., en GRACIA MARTÍN, L. (Coord.), Lecciones de consecuencias jurídicas del delito, cit., p. 66; GIL GIL, A. / LACRUZ LÓPEZ, J.M. / MELENDO PARDOS, M. / NÚÑEZ FERNÁNDEZ, J., Consecuencias jurídicas del delito, cit., p. 153; GUTIÉRREZ CASTAÑEDA, A., en ROCA DE AGAPITO, L. (Dir.), Las consecuencias jurídicas del delito, Tirant lo Blanch, Valencia, 2017, p. 53; PUENTE ABA, L.M., La pena de inhabilitación absoluta, cit., pp. 79 ss.; la misma autora, "La pena de inhabilitación especial para empleo o cargo público", en FARALDO CABANA, P. / PUENTE ABA, L.M. (Dir.), Las penas privativas de derechos y otras alternativas a la privación de libertad, Tirant lo Blanch, Valencia, 2013, p. 82; SÁNCHEZ MELGAR, J., "La pena de inhabilitación: consti- 
Esto viene corroborado precisamente por los arts. 63 y 66 del Estatuto Básico del Empleado Público, según los cuales la pena principal o accesoria de inhabilitación absoluta o especial produce la pérdida de la condición de funcionario público.

Esta cuestión fue el núcleo central de la ejecución del indulto en el "caso Gómez de Liaño", puesto que el Real Decreto 2392/2000, 1-12, que concedió esta medida de gracia, estableció expresamente que el perdón de la pena de inhabilitación especial determinaba el reingreso a la carrera judicial del condenado. Ya en ese caso el ATS 18-1-2001, relativo a la ejecución del indulto, estableció expresamente que no cabía tal reingreso, puesto que ello estaba "en contra de la literalidad del artículo 42 del Código Penal y del artículo 4 de la Ley de Indulto que solo permite el indulto de la pena que todavía no se hubiese cumplido o ejecutado"; en este supuesto, al haberse ejecutado ya el primer efecto de la pena de inhabilitación, esto es, la privación del empleo público (el Consejo General del Poder Judicial había cesado al magistrado el 3-11-1999), ya no cabía el perdón de este efecto de la sanción ${ }^{59}$.

Con carácter general, los Tribunales han venido reconociendo este carácter instantáneo y definitivo del primer efecto de la pena de inhabilitación, esto es, la privación del empleo o cargo público ${ }^{60}$. Por ello, deben rechazarse formas de expresión de la pena como la contenida en el citado ATSJ Cataluña 23-112017, que se refiere a "la privación definitiva durante el tiempo de dos años del empleo o cargo de funcionario de Gestión Proce-

tucionalidad, contenido y problemas", en AAVV, Constitución y garantias penales, CGPJ, Madrid, 2004, p. 353.

59 Vid. sobre toda la problemática que rodeó la concesión y ejecución de este indulto, PUENTE ABA, L.M., La pena de inhabilitación absoluta, cit., pp. 117 ss., destacadamente la referencia a la intervención del Tribunal de conflictos de jurisdicción, cuya sentencia 6/2001, de 13 de junio, estableció que era el Gobierno el competente para determinar el alcance del indulto, mientras que las cuestiones relativas al reingreso del condenado en la carrera judicial habían de ser fijadas por el Consejo General del Poder Judicial (p. 118).

60 Vid., por ejemplo, la STS 394/2014, 7-5 o la STS 965/2012, 19-9. 
sal y Administrativa de la Administración de Justicia que ostenta el penado, así como la imposibilidad o incapacidad para recuperar dicho empleo o cargo, o para acceder al empleo de Letrado de la Administración de Justicia, durante el mismo tiempo". Es evidente que solo podrá tener duración temporal la incapacidad para acceder a determinados empleos o cargos, pero la privación de un empleo o cargo no puede limitarse en el tiempo, pues de esta forma no podría calificarse de definitiva.

La comprensión clara de este efecto de la pena puede ser relevante no solo con respecto a la institución del indulto, sino en relación con otras posibles situaciones. Así, más recientemente, cabe citar la STS 314/2017, 3-5, donde se trataba la posibilidad de aplicar retroactivamente la norma penal más favorable, en relación con las penas privativas de derechos. Concretamente, se analizaba la posible aplicación retroactiva del art. $432 \mathrm{CP}$, donde se castiga la malversación, puesto que la LO 1/2015, 30-3, de reforma del Código Penal, modificó el tipo de pena prevista en el apartado 1 del precepto: la pena de inhabilitación absoluta fue sustituida en 2015 por la pena de inhabilitación especial para empleo o cargo público. El recurrente había sido condenado con fecha 13-1-2014 a la pena de inhabilitación absoluta, y solicitaba su sustitución por la pena de inhabilitación especial, introducida en este art. 432.1 CP en la reforma del Código Penal de 2015. Como bien razonó el Tribunal, la posible revisión de la pena no permitiría, en ningún caso, la restitución del empleo o cargo público perdidos, puesto que el condenado ya había sido privado de ellos con anterioridad a dicha reforma legal, y por lo tanto la aplicación retroactiva de la norma penal solo podría proyectarse sobre el segundo efecto de la pena que sí tiene una duración temporal, la incapacidad para acceder a empleos o cargos públicos. 


\section{La precisión de los empleos o cargos "análogos" afecta- dos por la condena}

La pena de inhabilitación especial para empleo o cargo público, además de privar al sujeto de un concreto empleo o cargo concretado en sentencia, le impide volver a acceder de nuevo a este mismo empleo o cargo, y a otros análogos, durante el tiempo de la condena. La principal dificultad a la hora de interpretar este efecto de la pena radica en qué se entiende por empleos o cargos "análogos" al concreto empleo o cargo sobre el que recae la pena, y que es objeto de especificación en la sentencia condenatoria. Acudiendo a la jurisprudencia, nuestros tribunales afirman que tal analogía habrá de deducirse de la interpretación de la concreta actividad desarrollada, objeto de privación en la sentencia, y del fin que con ella se persigue ${ }^{61}$; así, sería recomendable que la propia sentencia indicase algún criterio para efectuar esta interpretación analógica, de cara a facilitar una adecuada ejecución de esta pena ${ }^{62}$. Podría atenderse, por ejemplo, al tipo de función desempeñada ${ }^{63}$, al ámbito administrativo o territorial en el que se ejerce el empleo o cargo ${ }^{64}$, al

61 Vid. BOLDOVA PASAMAR, M.A., "Penas", cit., p. 130; FERNÁNDEZ DEL TORCO ALONSO, J.M., "La desaparición de la inhabilitación especial", Cuadernos de política criminal, n. ${ }^{\circ}$ 52, 1994, p. 119.

62 Vid. BOLDOVA PASAMAR, M.A., "Penas", cit., p. 130. Vid. por ejemplo STS 704/2011, 1-7.

63 Vid. por ejemplo ORTS BERENGUER, E. / GONZÁLEZ CUSSAC, J.L., Compendio de Derecho Penal. Parte general, cit., p. 472; TAMARIT SUMALLA, J.M., “Artículo 42”, en QUINTERO OLIVARES, G. (Dir.), Comentarios al Código Penal español, Tomo I, Thomson Reuters Aranzadi, Cizur Menor, 2016, p. 460.

64 Vid. BAUCELLS LLADÓS, J., “Artículos 41-43”, en CÓRDOBA RODA, J./ GARCÍA ARÁN, M. (Dirs.), Comentarios al Código penal. Parte general, cit., pp. 463-470.cit., p. 467; CORDERO LOZANO, C., Condenas penales privativas de libertad y de derechos, Bosch, Barcelona, 2010, p. 38; LLORCA ORTEGA, J., Manual de determinación de la pena, $6^{\mathrm{a}}$ ed. Tirant lo Blanch, Valencia, 2005, p. 242; POZUELO PÉREZ, L., Las penas privativas de derechos en el Código penal, Colex, Madrid, 1998, p. 42; REY HUIDOBRO, L.F., "Problemas de aplicación de las penas accesorias de inhabilitación y de suspensión", Actualidad penal, 2003-3, m. 1130; SERRANO BUTRAGUEÑO, I., “Artículo 42”, cit., p. 513; VAELLO ESQUERDO, 
concreto nivel jerárquico o al ejercicio de autoridad inherente al empleo o cargo, al manejo de fondos o numerario, o a la existencia de contacto con el público ${ }^{65}$. En cualquier caso, debería rechazarse el empleo de expresiones genéricas para determinar el carácter análogo de otros cargos o empleos que también podrán ser objeto de privación; por ejemplo, la mención de la incapacidad para acceder al "mismo empleo u otros similares", presente por ejemplo en la STS 887/2008, 10-12 ${ }^{66}$.

En resumen, los dos ejes que determinarían las pautas para determinar la analogía serían, por un lado, el tipo de función o actividad desempeñada, y por otro lado, la extensión del ámbito territorial para su ejercicio, con el objetivo de evitar que el sujeto pueda acceder a la misma función en otra zona geográfica diferente. La selección de los cargos o empleos afectados, en suma, ha de estar guiada por el bien jurídico afectado con la comisión del delito, puesto que para su salvaguarda ha de privarse al condenado de aquellos empleos o cargos en cuyo ejercicio pueda volver a afectar al mismo bien jurídico ${ }^{67}$.

E., Las consecuencias jurídicas del delito, Universidad de Alicante, 2006, p. 68; VALLDECABRES ORTIZ, I., VALLDECABRES ORTIZ, I., "De las penas privativas de derechos", en VIVES ANTÓN, T. S. (Coord.), Comentarios al Código Penal de 1995. Volumen I, Tirant lo Blanch, Valencia, 1996, p. 324; ZUBIRI DE SALINAS, F., "Las penas de inhabilitación y suspensión", en Revista Aragonesa de Administración Pública, n 11, 1997, p. 346.

65 Vid. estos tres últimos criterios en SERRERA CONTRERAS, P., "Las penas de inhabilitación y la condición de funcionario público", en Revista Andaluza de Administración Pública, $\mathrm{n}^{\circ}$ 58, 2005, p. 182.

66 Así, por ejemplo, deberían rechazarse expresiones empleadas por el TS como por ejemplo "otros cargos políticos de nombramiento o elección" (vid. SSTS 1-10-1993 y 10-6-1995): vid. BAUCELLS LLADÓS, J., “Artículos 41-43", cit., p. 468; LLORCA ORTEGA, J., Manual, cit., p. 241. No obstante, según la STC 151/1999, 14-9, es correcta y admisible la citada expresión, puesto que el condenado (por infidelidad en la custodia de documentos) no ha demostrado respeto por las reglas de juego para conseguir el voto de los ciudadanos, y por eso se desea apartarlo de cualquier cargo al que pueda acceder por elección popular. En este sentido, vid. las consideraciones de GILI PASCUAL, A., "La inhabilitación para empleo público en el Derecho penal actual", cit., p. 154, en contra de establecer una auténtica analogía en contra del reo.

67 Vid. así CARDENAL MONTRAVETA, S., “Artículo 42”, cit., pp. 214-215. 
Así, por ejemplo, en relación estrictamente con empleos públicos, pueden citarse ejemplos como los siguientes: privación del empleo de Mosso d'Esquadra, e incapacidad para acceder a Fuerzas y Cuerpos de Seguridad de la Administración estatal, autonómica o local (STS 910/2009, 25-9); inhabilitación especial para el cargo de juez o magistrado, sí como incapacidad para obtener durante el tiempo de la condena cualquier empleo o cargo con funciones jurisdiccionales o de gobierno dentro del Poder Judicial, o con funciones jurisdiccionales fuera del mismo (STS 79/2012, 9-2); o funcionario de Correos al que se le impide acceder a otro tipo de empleos o cargos que impliquen manejo de correspondencia o funciones parecidas a las desempeñadas por estos funcionarios (STS 2017/1993, 18-10) ${ }^{68}$.

En relación con cargos públicos, pueden ofrecerse como ejemplos: privación del cargo de alcalde, junto con la imposibilidad de acceder a los cargos de alcalde, teniente de alcalde, concejal o cualquier otro de naturaleza electiva y ámbito local que implique participación en el gobierno municipal (STS 704/2011, 1-7; STS 552/2006, 16-5); o privación del cargo de subdirector de Centro penitenciario e incapacidad para acceder a otros empleos o cargos de la Administración estatal, autonómica o local, que impliquen funciones de vigilancia, custodia o conducción de detenidos o presos (STS 196/1997, 17-2) ${ }^{69}$. También cabe referirse al caso de la STS 394/2014, 7-5 (caso Scala): aquí la inhabilitación especial privó del cargo de Consejero del Gobierno autonómico, e imposibilitó la obtención de otros puestos de gestión pública en el ámbito de la Administración estatal, autonómica, insular o local. En esta línea, también, la SAP Barcelona 347/2018, 26-4, que indicaba que "si las funciones en cuyo ejercicio se perpetraron los comportamientos delictivos fueron elec-

68 Vid. más ejemplos de establecimiento de la analogía, en relación tanto con empleos públicos como con cargos públicos, en CARDENAL MONTRAVETA, S., “Artículo 42”, cit., pp. 215-216; TAMARIT SUMALLA, J.M., "Artículo 42", cit., p. 460.

69 Estos dos ejemplos son mencionados por POZUELO PÉREZ, L., Las penas privativas, cit., p. 42. 
tivas, debe impedirse el acceso a cualquier otro cargo público electivo durante el tiempo de la condena en cualquier administración pública, nacional, autonómica o local dado que a aquella persona que se ha servido de su cargo electivo de naturaleza política para delinquir, se le impida su acceso a cualquier otro cargo público electivo durante el tiempo de la condena; carecería de toda lógica que se le permitiera acceder a otros cargos electivos, bien de la Comunidad Autónoma o del Estado, lo que dejaría sin contenido el expreso mandato del art. $42 \mathrm{CP}$. Todos ellos han sido considerados jurisprudencialmente pues de todos los cargos electivos de estos tres círculos se puede predicar la analogía que exige el art. $42 \mathrm{CP}$ por presentar rasgos comunes para la receptividad de los ciudadanos en cuanto a las exigencias de integridad de las personas que puedan ser los titulares de dichos cargos de representación popular". Finalmente, son importantes las precisiones de la STS 259/2015, 30-4, que, en relación con cargos municipales, estableció que los condenados no podrían acceder a cualesquiera otros cargos de naturaleza electiva y ámbito local que implicasen participación en el gobierno municipal, y asimismo otros análogos en el ámbito insular, autonómico o estatal. En la interpretación de tal analogía, la sentencia indicó, en relación con el condenado que ostentaba la doble condición de Alcalde y Senador en las Cortes Generales, que "no se desborda el límite de la extensión de la pena cuando se considera análoga la desarrollada en otros ámbitos de la administración como pueden ser el insular, autonómico o estatal, referida a las funciones de gobierno en el presente caso. Sin embargo, no debe alcanzar a otras funciones, como la legislativa, porque no sería análoga a las de gobierno, aun cuando sean electivas"70.

70 La propia sentencia del Tribunal Supremo reconoce que está tomando una decisión que pudiera parecer contradictoria con los pronunciamientos del Tribunal Constitucional en la STC 151/1999, 14-9. En este último caso, se desestimó el recurso de amparo presentado por una persona que había sido condenada a pena de inhabilitación especial, que se extendía a "todo cargo público electivo", de modo que determinó la pérdida de sus cargos de Alcalde y Senador. Si bien el Tribunal Constitucional argumenta que la privación de ambas clases de cargos estaría justificada por la ausencia de ejemplari- 
Por otro lado, no está de más puntualizar que si la prohibición recae sobre un concreto empleo público, aunque la analogía se fije en función del tipo de actividad e incluso se extienda su ámbito geográfico, no tiene por qué abarcar a cargos de naturaleza electiva, que constituyen un ámbito distinto de los empleos en la Administración pública; y a la inversa, la privación de un cargo público no tiene por qué afectar al acceso a empleos públicos al fijar los límites de la analogía.

Así, en relación con el primer tipo de supuestos, cabe citar el caso resuelto en la SAP Valencia 23-1-2017 y posteriormente en la STS 88/2018, 21-2. La sentencia de instancia había condenado sin más al acusado a la pena de inhabilitación especial para empleo o cargo público (esto es, sin precisar ni el concreto cargo o empleo afectado ni los cargos o empleos análogos); posteriormente, la AP Valencia dictó un Auto de aclaración de sentencia (de 10-2-2017), precisando el alcance de la pena de inhabilitación especial, que iría referida a "la privación del cargo efectivo de Alcalde electo, que desempeñaba durante la comisión de los hechos y que sigue desempeñando en la actualidad, junto con el tratamiento anejo al cargo, uso de medallas o distintivos cualesquiera; honores que le sean anejos, cobro de percepciones, dietas, recompensas o indemnizaciones, y cualesquiera otros emolumentos con cargo a fondos públicos que se encuentren previstos en la legislación de régimen local, debiendo extenderse a la incapacidad para obtener el mismo cargo, u otros análogos de prestación de servicios en régimen funcionarial en cualquier administración pública, nacional, autonómica o local". El TS efectuó posteriormente una restricción del alcance de los empleos o cargos análogos, con base en el hecho de que "las funciones en cuyo ejercicio se perpetraron los comportamientos

dad y confianza exigible a toda función pública, que se ha quebrado por la comisión del delito, también pone de manifiesto que la elección del cargo o empleo afectado ha de adaptarse a la singularidad de cada caso, precisión que justamente resalta el Tribunal Supremo en esta STS 259/2015, donde el cargo de Senador no fue objeto de privación ni tampoco abarcado por la analogía. 
delictivos, no fueron las derivadas de una situación funcionarial concreta, que permita proyectar la inhabilitación para la 'prestación de servicios en régimen funcionarial'; de modo que tal proyección de la inhabilitación para obtener además del mismo cargo, los análogos al mismo, a los que provengan de cualquier origen del cometido funcionarial de los enumerados en el art. 24 del Código Penal, resulta indebida, de conformidad con la doctrina jurisprudencial enunciada; debiendo restringirse por tanto a los de procedencia electiva; si bien, en cualquier administración pública, nacional, autonómica o local; pues es adecuada consecuencia que aquella persona que se ha servido de su cargo electivo de naturaleza política para delinquir, se le impida su acceso a cualquier otro cargo público electivo durante el tiempo de la condena; carecería de toda lógica que se le permitiera acceder a otros cargos electivos, bien de la Comunidad Autónoma o del Estado, lo que dejaría sin contenido el expreso mandato del art. 42 CP ( STS 436/2016, de 23 de mayo)".

Con respecto al segundo supuesto indicado, pueden citarse los casos de la STS 8/2018, 11-1, según la cual la pena de inhabilitación supone la pérdida definitiva del puesto de arquitecto municipal "así como la imposibilidad de obtener el mismo u otro similar como técnico en ese o cualquier otro ayuntamiento"; y más claramente, de la SAP Almería 449/2018, 28-9, sentencia en la que la pena de inhabilitación especial supone la imposibilidad de "desempeñar las funciones de secretario municipal, así como cualquier otro cargo análogo en la Administración, que sea de designación, excluidos los que lo sean por elección, en el ámbito local o municipal, insular, autonómico o estatal".

Finalmente, no está de más recordar la necesidad de precisión y taxatividad en la determinación de la analogía, al igual que se indicaba en relación con la selección del concreto cargo o empleo afectado. Obsérvese, por ejemplo, la STS 436/2016, 23 5 , que establece del siguiente modo los cargos o empleos análogos: en relación con el cargo de concejal, la sentencia se refiere a "cualquier otro cargo electivo de la Administración Local, de 
la Administración de las Comunidades Autónomas y de la Administración Estatal"; con respecto a los funcionarios públicos municipales, la sentencia establece la prohibición de "ocupar cualquier cargo de función pública en la Administración Local, Autonómica o Central" o la de desempeñar "cualquier otro cargo público de la Administración Local, Autónoma o Central".

Por lo que respecta a este último supuesto, relacionado con la privación de empleo a los condenados funcionarios públicos, sería recomendable que la analogía viniese establecida concretamente con respecto a otros empleos públicos (en las tres Administraciones indicadas), no en relación con "cualquier otro cargo público". Tal mención suscita la duda de si se veta el acceso solo a empleos públicos, o también a cargos de naturaleza electiva en tales ámbitos; indudablemente, de afectar también a cualquier tipo de cargo podría afirmarse que no se dan los presupuestos propios de la analogía.

En cuanto a la expresión de la inhabilitación referida al cargo de concejal, la analogía se establece en función del carácter electivo del cargo, extendiendo sus efectos a otros ámbitos geográficos más allá de la Administración local. Si bien este tipo de previsión, como se ha ido viendo, es usual en la fijación de la analogía relacionada con los cargos públicos, puede variar su extensión en función de las particularidades del caso concreto. Así, aquí cabe recordar la STS 259/2015, 30-4, en la que el condenado había cometido el delito en el ejercicio de un cargo público de libre designación en el Gobierno autonómico, pero en el momento del enjuiciamiento había pasado a ser miembro del Parlamento de la Comunidad Autónoma. La sentencia decretó que la pena de inhabilitación implicaba la "pérdida de su condición de Diputado electo de la Junta General del Principado de Asturias, así como la imposibilidad de concurrir a ningún tipo de elección o ser nombrado para puesto representativo o ejecutivo o gestor por una autoridad pública". Como se ve, la analogía no solo viene referida al cargo objeto de privación (Diputado autonómico) sino también al cargo que desempeñaba en el momento 
de comisión del delito (cargo de libre designación en el ámbito ejecutivo o gestor).

\section{Reflexión final}

Como se ha visto a lo largo de este trabajo, la pena de inhabilitación especial para empleo o cargo público puede plantear destacados problemas e interrogantes en el momento de su aplicación judicial. En primer lugar, se detecta en ocasiones una falta de precisión a la hora de imponer esta pena, cuestión especialmente relevante puesto que, a diferencia de la inhabilitación absoluta, en la inhabilitación especial es necesario indicar de forma específica en el fallo el concreto cargo o empleo público objeto de privación. Asimismo, como por definición la pena exige efectuar un ejercicio de analogía, es necesario partir de unas pautas interpretativas que fundamenten la extensión de la prohibición de acceso a otros cargos o empleos diversos del concreto que ostentaba el penado. Como se ha podido comprobar, no siempre los fallos condenatorios reflejan adecuadamente ambas exigencias, dificultando así una aplicación correcta de la pena de inhabilitación especial.

Aun respetando estas cuestiones básicas, las vicisitudes de aplicación de esta pena pueden ser muy numerosas. Aquí se han seleccionado aquellas que pueden resultar especialmente significativas a la hora de aplicar esta pena en relación con delitos de corrupción cometidos en el marco de la contratación con el sector público. Destacadamente, se ha analizado si puede constituir cargo público la actuación en el seno de sociedades mercantiles públicas y de corporaciones sectoriales de base privada, y asimismo, se ha tratado cómo puede calificarse la actividad realizada por un particular en el marco de la ejecución de un contrato del sector público de naturaleza administrativa. En relación con los dos primeros casos planteados, cabe afirmar que constituye cargo público la realización de funciones de dirección y control en el marco de ambas clases de entidades. Por lo 
que respecta a las sociedades mercantiles públicas, la jurisprudencia ha reconocido de forma general que quienes administran este tipo de entidades están ejerciendo una función pública, que implica la participación en una de las muy variadas modalidades de configuración de la Administración pública, que atiende a los intereses generales desde muy diversas formas de organización. Por consiguiente, lo relevante es la constatación del ejercicio de la función pública, al margen del concreto revestimiento formal que tal actividad puede presentar a lo largo de la evolución del Derecho administrativo. En relación con las corporaciones sectoriales de base privada, desempeñarán un cargo público (y así lo ha reconocido la jurisprudencia) quienes tengan atribuidas las facultades de disciplina y control de los miembros de la corporación, que son encomendadas por la ley o por la propia Administración con la finalidad, esencialmente, de regular el correcto ejercicio de una determinada actividad privada. Por último, puede resultar más problemático el tercer supuesto, el referido a aquellas personas físicas o jurídicas que concluyen un contracto (administrativo) con el sector público. En cierto modo, aquí también se aprecia una forma de descargar del núcleo de la Administración pública la prestación de determinados servicios públicos, pero con un grado de desvinculación mucho mayor que en el caso de las sociedades mercantiles públicas. Pueden encontrarse casos en que los Tribunales han considerado empleo público el ejercicio de determinadas actividades bajo la cobertura de uno de estos contratos; no obstante, la cuestión no es uniforme ni sencilla, y todo dependerá de la clase de contrato celebrado (ya que será más frecuente en los supuestos de contratos de concesión de servicios y contratos de servicios), del tipo de actividad realizada (puesto que debería poder calificarse como la participación en una auténtica función pública), y del grado de responsabilidad de la persona actuante (ya que, en el caso de que sea una persona jurídica quien concluya esta clase de contratos, podría plantearse la restricción de tal consideración a quienes constituyen sus gestores). 
La concreción exacta del empleo o cargo público objeto de privación resulta imprescindible no solo porque así lo exige el art. $42 \mathrm{CP}$, sino porque su determinación no tiene por qué ser tan obvia como aparece en un principio. Así, la privación del empleo o cargo es sencilla cuando el condenado solo posee uno claramente identificable, pero puede plantearse un amplio abanico de situaciones, que giran fundamentalmente en torno a la posesión simultánea o sucesiva de distintos empleos o cargos públicos, tal y como se ha ejemplificado con distintos supuestos presentados en este trabajo. Si bien el Código Penal (y así lo ha reiterado la jurisprudencia) solo exige la vinculación entre el empleo o cargo y el delito cometido cuando la pena se aplica como accesoria (art. $55 \mathrm{CP}$ ), debería requerirse tal conexión también cuando se aplica como pena principal, pues constituiría un criterio adecuado para seleccionar el concreto empleo o cargo objeto de privación. Lo que no podría admitirse, dada la expresión legal de la pena, es la fragmentación del empleo o cargo, de tal modo que al sujeto se le prive del ejercicio de determinadas actividades pero conserve la titularidad del puesto desempeñado. Si bien ello podría contribuir a reducir el carácter especialmente aflictivo de la pena en algunos casos, tal opción solo sería posible si la pena viniera definida legalmente como una inhabilitación para funciones públicas, no estrictamente para cargos o empleos públicos. Tal naturaleza gravosa de la pena se acentúa por el hecho de que la privación del cargo o empleo es de carácter definitivo, de tal modo que no se puede recuperar una vez cumplida la condena, y además tal efecto de la pena, una vez ejecutado, no puede ser eliminado ni por la concesión de un indulto ni por efecto de la aplicación retroactiva de la norma penal más favorable.

Por último, se ha prestado atención a las posibles pautas que pueden dotar de contenido a la analogía prevista en la aplicación de esta pena. Los Tribunales tendrán que escoger qué empleos o cargos públicos, por su similitud con el empleo o cargo objeto de privación, han de estar vetados al penado durante el tiempo de la condena. Con carácter general, atendiendo 
al fundamento de esta pena, el eje fundamental para determinar la analogía sería el tipo de actividad o función desempeñada, siendo necesario también fijar el alcance de tal prohibición, esto es, concretar a qué ámbito geográfico o a qué niveles de la Administración pública se refiere. Finalmente, es importante tener en cuenta también que la privación de un empleo público no tiene por qué implicar automáticamente la prohibición de acceso a cargos públicos (y lo mismo a la inversa, esto es, privar de un cargo público no ha de afectar obligatoriamente a la posibilidad de obtener un empleo público), sino que, a lo sumo, esta prescripción tendría que venir fundamentada en alguno de los criterios materiales anteriormente enunciados para determinar la analogía.

\section{Bibliografía}

ALONSO PÉREZ, F., Delitos cometidos por los funcionarios públicos en el nuevo Código penal, Dykinson, Madrid, 2000.

ARIÑO ORTIZ, G., Principios de Derecho público económico. Modelo de Estado, gestión pública, regulación económica, Comares, Granada, 2004.

ARIÑO ORTIZ, G. / LÓPEZ DE CASTRO, L., ¿Privatizar el Estado? Un retroceso en el camino de la Historia o la antitesis del Estado de Derecho, Fundación BBV, Bilbao, 1994.

BAUCELLS LLADÓS, J., "Artículos 41-43”, en CÓRDOBA RODA, J./ GARCÍA ARÁN, M. (Dirs.), Comentarios al Código penal. Parte general, Marcial Pons, Madrid, 2011, pp. 463-470.

BOLDOVA PASAMAR, M.A., en GRACIA MARTÍN, L. (Coord.), Tratado de las consecuencias jurídicas del delito, Tirant lo Blanch, Valencia, 2006.

BOLDOVA PASAMAR, M.A., en GRACIA MARTÍN, L. (Coord.), Lecciones de consecuencias jurídicas del delito, Tirant lo Blanch, Valencia, 2016. 
CABEZAS HERNÁNDEZ, M.T., Las Cámaras de comercio, industria y navegación de España: naturaleza jurídica y funciones, Atelier, Barcelona, 2002.

CARDENAL MONTRAVETA, S., "Artículo 42", en CORCOY BIDASOLO, M. / MIR PUIG, S. (Dir.), Comentarios al Código Penal, Tirant lo Blanch, Valencia, 2015, pp. 211218.

CASTRO MORENO, A., La malversación de caudales en el Código penal de 1995, Tirant lo Blanch, Valencia, 2001.

CORDERO LOZANO, C., Condenas penales privativas de libertad y de derechos, Bosch, Barcelona, 2010.

DESDENTADO AROCA, E., La crisis de identidad del Derecho Administrativo: privatización, huida de la regulación pública y Administraciones independientes, Tirant lo Blanch, Valencia, 1999.

FERNÁNDEZ ASTUDILLO, J.M., El nuevo régimen de contratación pública, Bosch Wolters Kluwer, Madrid, 2018.

FERNÁNDEZ DEL TORCO ALONSO, J. M., "La desaparición de la inhabilitación especial", en Cuadernos de Politica Criminal, no 52, 1994, pp. 113-125.

FERNÁNDEZ DOMÍNGUEZ, J.J. / RODRÍGUEZ ESCANCIANO, S., Hacia un nuevo régimen jurídico del personal al servicio de las Administraciones públicas, Instituto Andaluz de Administración Pública, Sevilla, 2006.

FERNÁNDEZ FARRERES, G., "Administraciones instrumentales", en AAVV, Estudios para la reforma de la Administración pública, INAP, Madrid, 2004, pp. 341-364.

FERNÁNDEZ FARRERES, G., "Corporaciones de Derecho público", AAVV, Estudios para la reforma de la Administración pública, INAP, Madrid, 2004, pp. 365-374.

GARCÍA DE ENTERRÍA, E. / FERNÁNDEZ, T.R., Curso de Derecho administrativo I, Civitas Thomson Reuters, Cizur Menor, 2017.

GARRIDO FALLA, F. / PALOMAR OLMEDA, A. / LOSADA GONZÁlEZ, H., Tratado de Derecho administrativo. Parte general, Tecnos, Madrid, 2010. 
GIL GIL, A. / LACRUZ LÓPEZ, J.M. / MELENDO PARDOS, M. / NÚÑEZ FERNÁNDEZ, J., Consecuencias jurídicas del delito. Regulación y datos de la respuesta a la infracción penal en España, Dykinson, Madrid, 2018.

GILI PASCUAL, A., "La inhabilitación para empleo público en el Derecho penal actual", en Cuadernos de política criminal, $n^{\circ} 124,2018$, pp. 145-172.

GONZÁLEZ CUSSAC, J.L., El delito de prevaricación de autoridades y funcionarios públicos, Tirant lo Blanch, Valencia, 1997.

GONZÁLEZ LÓPEZ, J.J., "La huida del Derecho administrativo como factor criminógeno", en Revista de Derecho Penal y Criminología, Vol. 16, 2016, pp. 375-412.

GOSÁLBEZ PEQUEÑO, H., "Las prohibiciones de contratar", en GAMERO CASADO, E. / GALLEGO CÓRCOLES, I. (Dir.), Tratado de contratos del sector público, Tomo II, Tirant lo Blanch, Valencia, 2018, pp. 1286-1350.

GUTIÉRREZ CASTAÑEDA, A., Las penas privativas de derechos politicos y profesionales, Tirant lo Blanch, Valencia, 2012.

GUTIÉRREZ CASTAÑEDA, A., en ROCA DE AGAPITO, L. (Dir.), Las consecuencias jurídicas del delito, Tirant lo Blanch, Valencia, 2017.

JAVATO MARTÍN, A.M., "El concepto de funcionario y autoridad a efectos penales", en Revista Jurídica de Castilla y León, 2011, n 23, pp. 145-172.

LANDROVE DÍAZ, G., Las consecuencias jurídicas del delito, Tecnos, Madrid, 2005.

LLORCA ORTEGA, J., Manual de determinación de la pena, $6^{\mathrm{a}}$ ed. Tirant lo Blanch, Valencia, 2005.

LÓPEZ CANDELA, J.E., Sobre la necesidad de un concepto de servicio público, CGPJ, Madrid, 2004.

LÓPEZ GONZÁLEZ, J.L., Los Colegios profesionales como corporaciones de Derecho público: un estudio en clave constitucional, Nomos, Valencia, 2001. 
LÓPEZ BARJA DE QUIROGA, J., Tratado de Derecho Penal. Parte general, Civitas Thomson Reuters, Cizur Menor, 2010.

LÓPEZ MARTÍN DE LA VEGA, R., La huelga de funcionarios públicos y el Código Penal, Bomarzo, Albacete, 2005.

MANENT ALONSO, L., "Contrato de concesión de servicios", en RECUERDA GIRELA, M.A. (Dir.), Comentarios a la nueva Ley de contratos del sector público, Civitas Thomson Reuters, Cizur Menor, 2018, pp. 160-167.

MANZANARES SAMANIEGO, J.L., Comentarios al Código Penal español, Wolters Kluwer, Las Rozas, 2016.

MAPELLI CAFFARENA, B., Las consecuencias jurídicas del delito, Civitas Thomson Reuters, Madrid, 2011.

MAPELLI CAFFARENA, B., "La pena de inhabilitación absoluta, ¿es necesaria?", en Cuadernos de política criminal, $\mathrm{n}^{\mathrm{o}}$ 108, 2012, pp. 5-30.

MARTÍN LORENZO, M., "Concepto penal de funcionario y externalización de funciones públicas”, en MAQUEDA ABREU, M. / MARTÍN LORENZO, M. / VENTURA PÜSCHEL, A. (Coord.), Derecho Penal para un estado social y democrático de derecho. Estudios penales en homenaje al profesor Emilio Octavio de Toledo y Ubieto, Universidad Complutense de Madrid, Madrid, 2016, pp. 209-230.

MARTÍN - RETORTILLO BAQUER, S., "Reflexiones sobre la 'huida' del Derecho administrativo", en Revista de Administración pública, $\mathrm{n}^{\mathrm{o}}$ 140, 1996, pp. 25-68.

MIR PUIG, C., Los delitos contra la Administración pública en el nuevo Código penal, Bosch, Barcelona, 2000.

MIR PUIG, S. / GÓMEZ MARTÍN, V., “Artículo 24”, en CORCOY BIDASOLO, M. / MIR PUIG, S. (Dir.), Comentarios al Código Penal, Tirant lo Blanch, Valencia, 2015, pp.156-158.

MIR PUIGPELAT, O., Globalización, Estado y Derecho. Las transformaciones recientes del Derecho administrativo, Civitas, Madrid, 2004. 
NÚÑEZ SÁNCHEZ, F., “Contrato de servicios”, en RECUERDA GIRELA, M.A. (Dir.), Comentarios a la nueva Ley de contratos del sector público, Civitas Thomson Reuters, Cizur Menor, 2018, pp. 173-177.

OLAIZOLA NOGALES, I., "Concepto de funcionario público a efectos penales", en ASÚA BATARRITA, A. (Ed.), Delitos contra la Administración pública, Instituto Vasco de Administración Pública, Bilbao, 1997, pp. 77-84.

OLAIZOLA NOGALES, I., El delito de cohecho, Tirant lo Blanch, Valencia, 1999.

ORTS BERENGUER, E. / GONZÁLEZ CUSSAC, J.L., Compendio de Derecho Penal. Parte general, Tirant lo Blanch, Valencia, 2017.

PALOMAR OLMEDA, A. I VÁZQUEZ GARRANZO, J., Practicum Función pública 2017, Thomson Reuters, Cizur Menor, 2016.

PARADA VÁZQUEZ, J.R., Derecho administrativo I, Ediciones Académicas, Madrid, 2017.

PARADA VÁZQUEZ, J.R., Derecho administrativo II, Ediciones Académicas, Madrid, 2018.

PARADA, R. / FUENTETAJA, J., Derecho de la función pública, Civitas Thomson Reuters, Cizur Menor, 2019.

PAREJO ALFONSO, L., Lecciones de Derecho administrativo, Tirant lo Blanch, Valencia, 2018.

POZUELO PÉREZ, L., Las penas privativas de derechos en el Código penal, Colex, Madrid, 1998.

PUENTE ABA, L.M., La pena de inhabilitación absoluta, Comares, Granada, 2012.

PUENTE ABA, L.M., "La pena de inhabilitación especial para empleo o cargo público", en FARALDO CABANA, P. / PUENTE ABA, L.M. (Dir.), Las penas privativas de derechos y otras alternativas a la privación de libertad, Tirant lo Blanch, Valencia, 2013, pp. 75-96.

QUERALT, J.J, "El concepto de funcionario público", en Cuadernos de política criminal, 1985, n² 27, pp. 477-508. 
QUESADA LUMBRERAS, J.E., en CASTILLO BLANCO, F.A. (Dir.), Manual de empleo público, Iustel, Madrid 2009, pp. 693-721.

QUINTERO OLIVARES, G., “Artículo 24”, en QUINTERO OLIVARES, G. (Dir.), Comentarios al Código Penal español, Tomo I, Thomson Reuters Aranzadi, Cizur Menor, 2016, pp. 330-335.

RAMON RIBAS, E., "La derogación jurisprudencial del artículo 24.2 CP (concepto de funcionario público)" en Estudios Penales y Criminológicos, 2014, vol. XXXIV, pp. 173-223.

RAMOS VÁZQUEZ, J.A., "La pena de inhabilitación especial para cualquier otro derecho", en FARALDO CABANA, P. / PUENTE ABA, L.M. (Dir.), Las penas privativas de derechos y otras alternativas a la privación de libertad, Tirant lo Blanch, Valencia, 2013, pp. 211-228.

REBOLLO PUIG, M. / FALCÓN Y TELLA, R. / LÓPEZ BENÍTEZ, M., Naturaleza y régimen jurídico de las cofradías de pescadores, Universidad de Córdoba, 1996.

REY HUIDOBRO, L. F., "Problemas de aplicación de las penas accesorias de inhabilitación y de suspensión", Actualidad penal 2003-3, m. 1123-1149.

RÍOS, J. / PASCUAL, E. / ETXEBARRIA, X., Manual sobre las consecuencias jurídicas del delito: su determinación y aplicación, Universidad Pontificia de Comillas, Madrid, 2016.

RIVERO ORTEGA, R., Administraciones públicas y Derecho privado, Marcial Pons, Madrid, 1998.

ROCA AGAPITO, L., El delito de malversación de caudales públicos, Bosch, Barcelona, 1999.

ROCA AGAPITO, L., "Concepto de autoridad y de funcionario público a efectos penales", en Revista Aranzadi de Derecho y Proceso Penal, 2013, n 31, pp. 1-21.

SALOM PARETS, A., Los Colegios profesionales, Atelier, Barcelona, 2007. 
SÁNCHEZ MELGAR, J., "La pena de inhabilitación: constitucionalidad, contenido y problemas", en AAVV, Constitución y garantías penales, CGPJ, Madrid, 2004, pp. 327-365.

SÁNCHEZ MORÓN, M., Derecho administrativo. Parte general, Tecnos, Madrid, 2018. https://doi.org/10.18042/ cepc/rap.206.02

SÁNCHEZ MORÓN, M., Derecho de la función pública, Tecnos, Madrid, 2018.

SÁNCHEZ MORÓN, M., "El retorno del Derecho administrativo", en Revista de Administración Pública, nº 206, 2018, pp. 37-66. https://doi.org/10.18042/cepc/rap.206.02

SANTAMARÍA PASTOR, J.A., Principios de Derecho Administrativo General II, Iustel, Madrid, 2018.

SANTAOLALla LÓPEZ, F., Derecho constitucional, Dykinson, Madrid, 2010.

SERRERA CONTRERAS, P., "Las penas de inhabilitación y la condición de funcionario público", en Revista Andaluza de Administración Pública, $\mathrm{n}^{\circ}$ 58, 2005, pp. 177-186.

TAMARIT SUMALLA, J.M., “Artículo 42”, en QUINTERO OLIVARES, G. (Dir.), Comentarios al Código Penal español, Tomo I, Thomson Reuters Aranzadi, Cizur Menor, 2016, pp. 458-460.

VAELLO ESQUERDO, E., Las consecuencias jurídicas del delito, Publicaciones de la Universidad de Alicante, Alicante, 2006.

VALCÁRCEL FERNÁNDEZ, P., "La delimitación de los tipos contractuales", en GIMENO FELIÚ, J.M., Estudio sistemático de la Ley de Contratos del Sector Público, Aranzadi Thomson Reuters, Cizur Menor, 2018, pp. 411-476.

VALEIJE ÁLVAREZ, I., "Reflexiones sobre los conceptos penales de funcionario público, función pública y personas que desempeñan una función pública", en Cuadernos de política criminal, 1997, $\mathrm{n}^{\circ} 62$, p. 435-498. 
VALLDECABRES ORTIZ, I., "De las penas privativas de derechos", en VIVES ANTÓN, T. S. (Coord.), Comentarios al Código Penal de 1995. Volumen I, Tirant lo Blanch, Valencia, 1996, pp. 314-339.

VAQUER CABALLERÍA, M., "De nuevo sobre la doctrina europea de los servicios de interés general: los problemas para definir la familia de los 'servicios sociales' y su aplicación en materia de vivienda", en Revista General de Derecho administrativo, $\mathrm{n}^{\circ} 25,2010$, pp. 1-19.

VÁZQUEZ - PORTOMEÑE SEIJAS, F., Los delitos contra la Administración Pública. Teoría general, Universidade de Santiago de Compostela, 2003.

ZUBIRI DE SALINAS, F., "Las penas de inhabilitación y suspensión", en Revista Aragonesa de Administración Pública, $\mathrm{n}^{\mathrm{o}} 11,1997$, pp. 335-355. 